\title{
Solubility and Diffusional Uptake of Hydrogen in Quartz at High Water Pressures: Implications for Hydrolytic Weakening
}

\author{
A. K. KRONENBERG ${ }^{1}$ AND S. H. KirbY \\ U.S. Geological Survey, Menlo Park, California \\ R. D. AINEs ${ }^{2}$ AND G. R. Rossman
}

Division of Geological and Planetary Sciences, California Institute of Technology, Pasadena

\begin{abstract}
Attempts to introduce molecular water into dry, natural quartz crystals by diffusive transport and thus weaken them hydrolytically at $T=700^{\circ}-900^{\circ} \mathrm{C}$ and $P_{\mathrm{H}_{2} \mathrm{O}}=400-1550 \mathrm{MPa}$ have failed. Infrared spectroscopy of hydrothermally annealed single crystals of natural quartz reveals the diffusive uptake of interstitial hydrogen (resulting in hydroxyl groups) at rates similar to those previously proposed for intracrystalline water at high water pressures. The solubility of interstitial hydrogen at these conditions is independent of temperature and pressure; instead, it depends upon the initial aluminum concentration by the local charge neutrality condition $\left[\mathrm{H}_{\mathrm{i}}{ }^{\circ}\right]=\left[\mathrm{Al}_{\mathrm{si}}{ }^{\prime}\right]$. The rate of interstitial hydrogen diffusion parallel to $c$ is given by an Arrhenius relation with $D_{0}=1.4 \times 10^{-1} \mathrm{~m}^{2} / \mathrm{s}$ and $Q=200 \pm 20 \mathrm{~kJ} / \mathrm{mol}$, in close agreement with $\mathrm{H}$ diffusivities reported for much lower pressures $\left(P_{\mathrm{H}_{2} \mathrm{O}}=2.5 \mathrm{MPa}\right)$. Deformation experiments following hydrothermal annealing show no mechanical weakening, and the lack of any detectable broadband absorption associated with molecular water shows that the diffusion rates of structural water are much lower than those of hydrogen. These results are consistent with the available oxygen diffusion data for quartz and with the failure to observe weakening in previous studies of quartz deformation at pressures of 300-500 MPa; they call into question the rapid rates of diffusion originally suggested for the hydrolytic weakening defect. It is suggested that the observed weakening in many previous experiments was complicated by microcracking processes in response to nonhydrostatic stresses and low effective confining pressures. Extensive microcracking may provide a mechanism for molecular water to enter quartz and allow local plastic deformation to occur. It does not appear that molecular water can diffuse far enough into uncracked quartz to allow hydrolytic weakening over annealing times that are feasible in the laboratory.
\end{abstract}

\section{INTRODUCTION}

In a study which has influenced the last 20 years of research of the mechanical properties of rocks, Griggs and Blacic [1964, 1965] reported a dramatic effect of water on the yield strength of quartz. Single crystals of Brazilian quartz, deformed in the $\mathrm{O}^{+}$orientation $\left(\sigma_{1}\right.$, the maximum principal compressive stress, at $45^{\circ}$ to $a$ and $c$ ) at elevated temperatures and confining pressures of 1000-1500 $\mathrm{MPa}$, yielded at stresses exceeding $2000 \mathrm{MPa}$ under dry conditions, whereas other specimens, annealed in talc assemblies above the dehydration temperature of talc and subsequently deformed, yielded at stresses of only 200-400 MPa (Figure 1). From these experiments originated the hypothesis, which is widely accepted today, that quartz (and other silicates) may be weakened by the addition of water through a hydrolysis reaction [Griggs, 1967]. Measurements of low yield strengths of synthetic quartz crystals, which contain large concentrations of water, confirmed that the strength of synthetic quartz is directly related to its water content [e.g., Griggs and Blacic, 1965; Griggs, 1967; Baëta and Ashbee, 1967, 1969a, b; Kirby and McCormick, 1979]. The water in synthetic quartz was found to occur in

\footnotetext{
${ }^{1}$ Now at Center for Tectonophysics, College of Geosciences, Texas A\&M University, College Station.

${ }^{2}$ Now at Lawrence Livermore National Laboratory, Earth Sciences Department, Livermore, California.
}

Copyright 1986 by the American Geophysical Union.

Paper number 5B5820.

0148-0227/86/005B-5820\$05.00 two distinct forms: interstitial hydrogen (hydroxyl groups) and a second water form which results in a "broadband" absorption in the infrared region at approximately $3 \mu \mathrm{m}$ and is attributable to molecular water [Aines et al., 1984]. It is this second water form that is strongly correlated with the strength of quartz [e.g., Kirby and McCormick, 1979; Kekulawala et al., 1981]. The presence of this molecular water in weak, synthetic crystals suggested that similar water must be taken up by initially dry, natural crystals by solid-state diffusive transport during high-pressure annealing [Blacic, 1971, 1975].

Attempts to reproduce the initial hydrolytic weakening experiments on natural quartz crystals at confining pressures of 300-500 MPa failed, however, both in the lack of any significant mechanical weakening and in the lack of infrared (IR) absorptions which resemble the "broadband" absorption of synthetic crystals [Paterson and Kekulawala, 1979; Kekulawala et al., 1981]. This discrepancy therefore led to the suggestion [Hobbs and Tullis, 1979; Paterson and Kekulawala, 1979; Tullis et al., 1979; Blacic, 1981; Kronenberg and Tullis, 1984] that high confining pressures, of the order of $1000-1500 \mathrm{MPa}$, were necessary to increase the solubility and/or diffusion rate of water in quartz. This suggestion, although supported by the recent investigations of Ord and Hobbs [1983, 1986] and Mackwell and Paterson [1985], is in direct conflict with the results of our current study.

Recent spectroscopic work on natural and synthetic quartz [Aines et al., 1984] has shown that the mechanically active water which results in the broad IR absorption is molecular water, in small groups of less than several hundred molecules. This is a markedly different environment from that of the hydrogen interstitials, which occur as isolated hydroxyl 

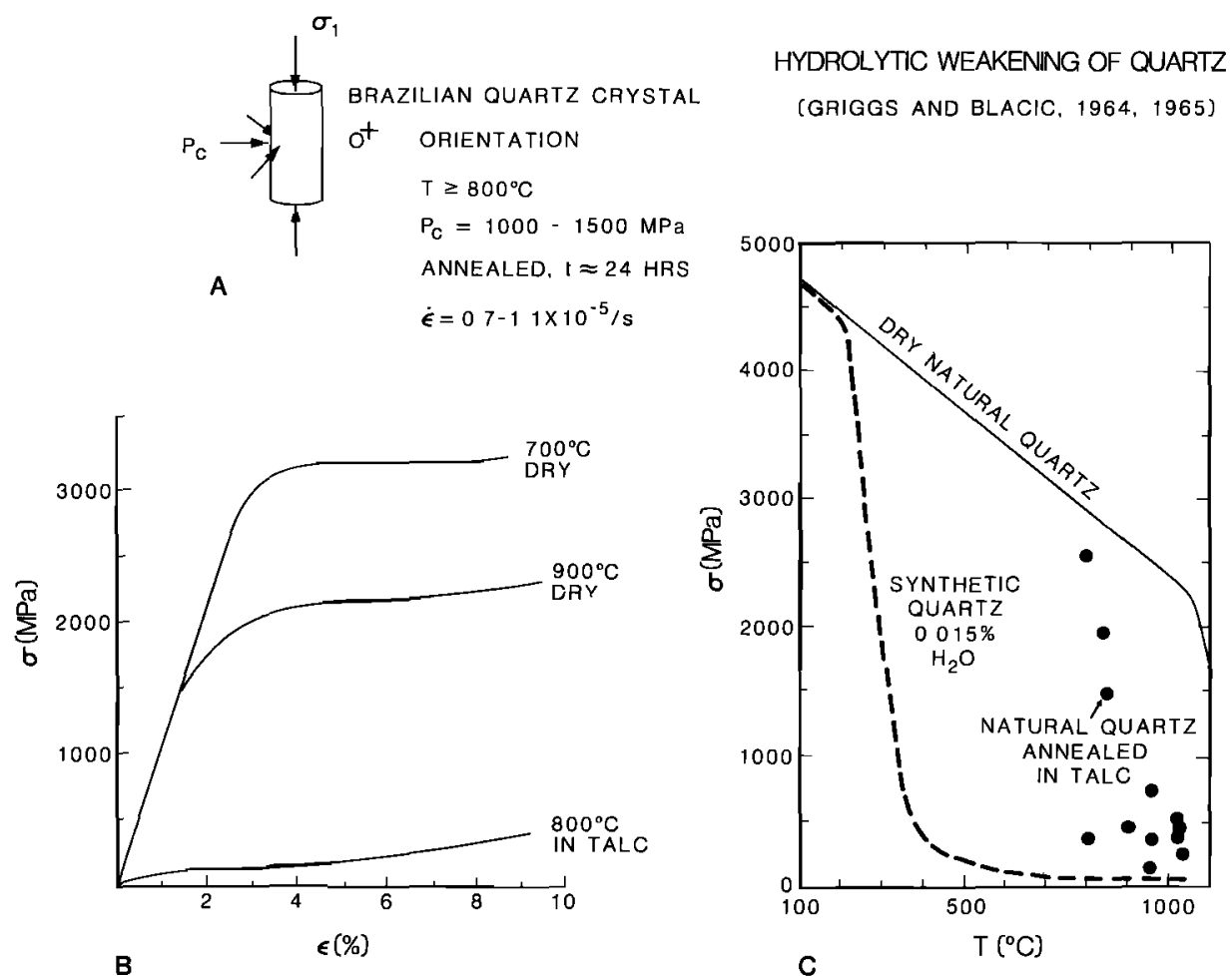

(GRIGGS AND BLACIC, 1964, 1965)

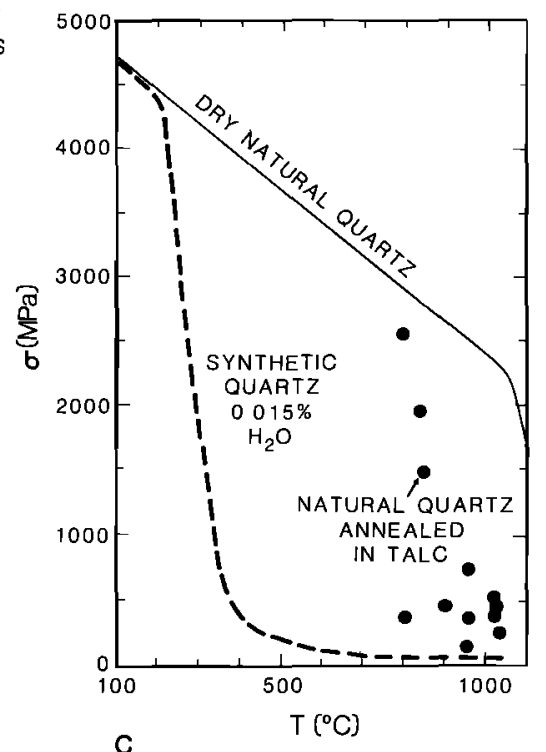

Fig. 1. Hydrolytic weakening of quartz. (a) In their original discovery of hydrolytic weakening, Griggs and Blacic $[1964,1965]$ shortened single crystals of Brazilian quartz (A-1) in the $\mathrm{O}^{+}$orientation at elevated temperatures $T$ and confining pressures $P_{c \cdot}$ (b) Stress $\sigma$ - strain $\varepsilon$ plot of quartz single crystals deformed under dry conditions and in talc assembly. Dry crystals yielded at $\sigma$ in excess of $2000 \mathrm{MPa}$, whereas samples, hydrothermally treated in talc assemblies, yielded at stresses of only 200-400 MPa. (c) Although the results for hydrothermally annealed Brazilian quartz crystals show a great deal of scatter, they fall within an envelope defined by the $\sigma-T$ relationship for dry Brazilian quartz and for synthetıc quartz crystals which contain relatively large concentrations of water.

groups. The ease with which the two forms of hydrogen may be differentiated suggested that a quantitative spectroscopic evaluation of the hydrogen content of annealed, initially dry quartz of the type used by Griggs and Blacic would allow us to determine the extent to which water uptake can be expected to occur under natural conditions.

In an attempt to determine the solubility and diffusional transport of molecular water at high pressures, we have annealed single crystals of dry Brazilian and Swiss quartz hydrostatically over the same temperature interval as that of the discovery experiments and at water pressures of $400-1550$ $\mathrm{MPa}$. Hydrogen-related defects incorporated during the hydrothermal anneals were then characterized by measuring IR absorptions due to $\mathrm{O}-\mathrm{H}$ stretching at room temperature $(\sim 300 \mathrm{~K})$ and at $77 \mathrm{~K}$ and their mechanical influence tested in deformation experiments at confining pressures of $\sim 1500$ $\mathrm{MPa}$. Because these experiments failed to exhibit evidence of structurally incorporated molecular water or any mechanical weakening, additional experiments were done using talc assemblies like those used by Griggs and Blacic [1964, 1965].

The results reported here for pressures up to $\sim 1500 \mathrm{MPa}$ suggest that the diffusion of molecular water is too slow for any significant penetration of large (millimeter scale) single crystals, consistent with the analogous studies of Paterson and Kekulawala [1979] and Kekulawala et al. [1981] at lower pressures in a gas apparatus. Hydrogen, on the other hand, does enter the quartz structure at rates sufficiently large for equilibration. These rates are unaffected by pressure up to $1550 \mathrm{MPa}$, and the incorporation of hydrogen on interstitial sites has no apparent mechanical effect, in accord with pre- vious work. Specimens which have been annealed and deformed in talc assemblies were weakened. However, careful examination of these samples suggests that microcracking, in addition to dislocation slip, is an important process under nonhydrostatic conditions and low effective confining pressures serving to reduce the diffusional penetration distances for molecular water. Similarly, we believe that the observed weakening of large single crystals by Griggs and Blacic [1964], 1965], Hobbs and Tullis [1979], Ord and Hobbs [1983, 1986],

TABLE 1. Chemical Analyses of Quartz Starting Materials

\begin{tabular}{ccc}
\hline $\begin{array}{c}\text { Trace } \\
\text { Element }\end{array}$ & $\begin{array}{c}\text { Crystal A-1, } \\
\text { Brazil, Concentration } \\
\text { in Atom } \mathrm{ppm} / \mathrm{Si}\end{array}$ & $\begin{array}{c}\text { Crystal Q-37, } \\
\text { Switzerland, Concentration } \\
\text { in Atom Ppm/Si }\end{array}$ \\
\hline $\mathrm{H}$ & $35 \pm 10^{a}$ & $96 \pm 10^{a}$ \\
$\mathrm{Li}$ & $40^{b}$ & $140^{b}$ \\
$\mathrm{Na}$ & $150^{c}$ & $25^{d}$ \\
$\mathrm{~K}$ & $19^{c}$ & $<13^{c}$ \\
$\mathrm{Mg}$ & $7^{b}$ & $7^{b}$ \\
$\mathrm{Cr}$ & $<6^{b}$ & $<6^{b}$ \\
$\mathrm{Mn}$ & $<1^{b}$ & $<1^{b}$ \\
$\mathrm{Fe}$ & $16 \pm 2^{b}$ & $<3^{b}$ \\
$\mathrm{Al}$ & $91 \pm 1^{b}$ & $300^{d}$ \\
\hline
\end{tabular}

${ }^{a}$ Analysis by infrared spectroscopy, present study.

${ }^{b}$ Analysis by quantitative emission spectroscopy, P. Klock and $T$ Fries, analysts, U.S. Geological Survey, Menlo Park.

'Analysis by flame photometry, P. Klock, analyst, U.S. Geological Survey, Menlo Park.

AAnalyses from Bambauer [1961]. 


\section{ANNEALING EXPERIMENTS IN PISTON-CYLINDER APPARATUS}

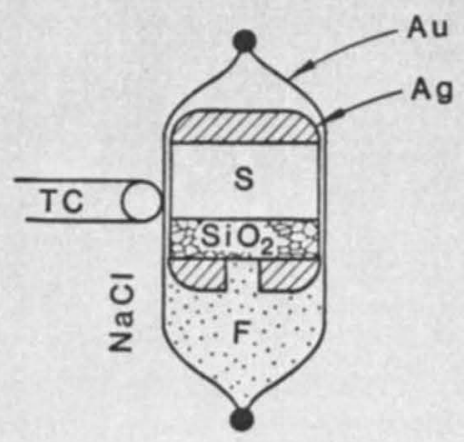

$$
\begin{aligned}
& \mathrm{T}=700^{\circ}-900^{\circ} \mathrm{C} \\
& \mathrm{P}_{\mathrm{C}}=1000-1500 \mathrm{MPa}
\end{aligned}
$$

A

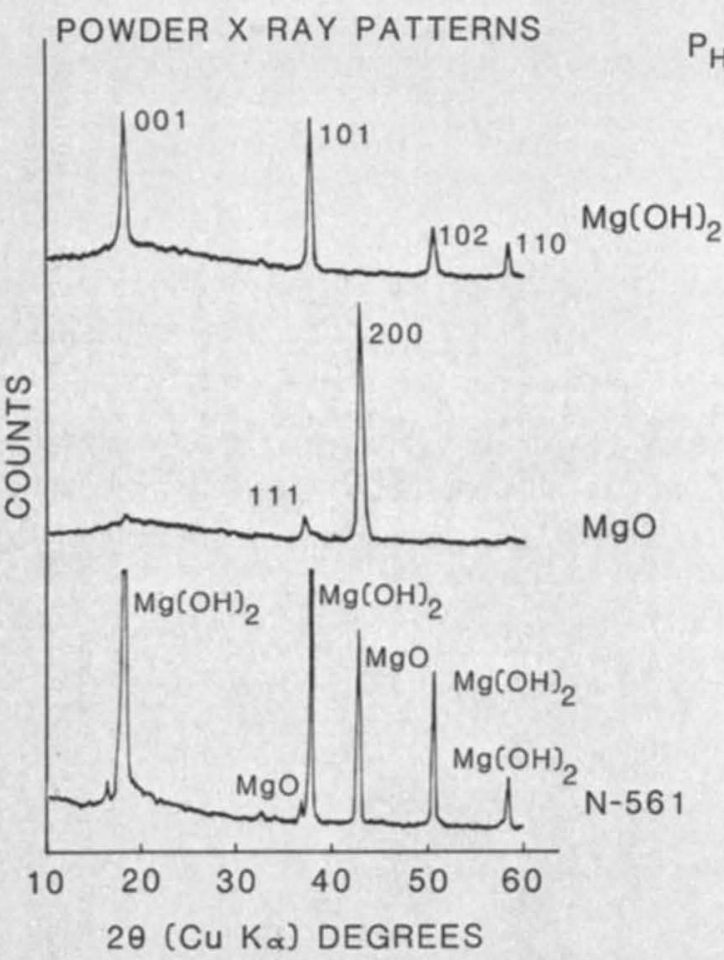

C

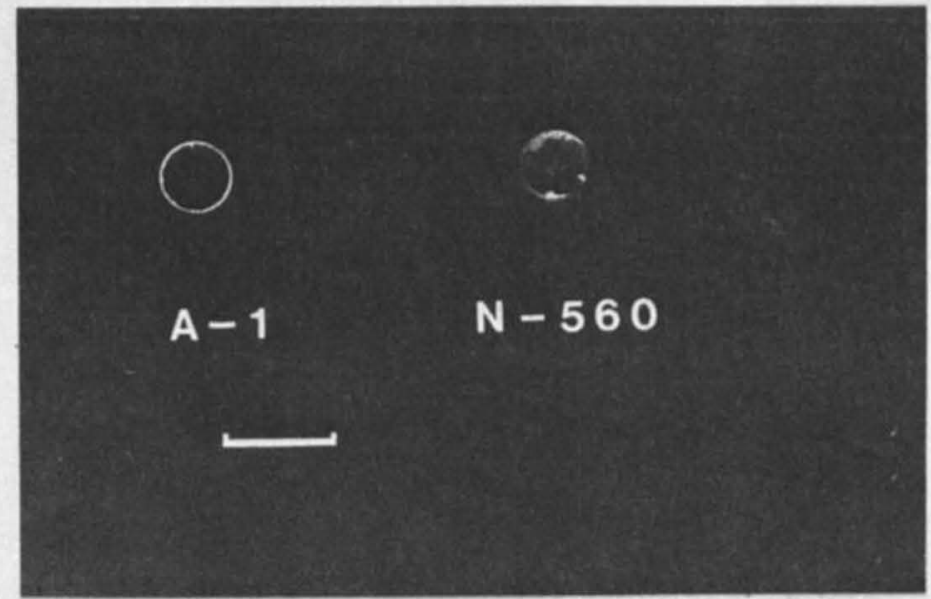

B 

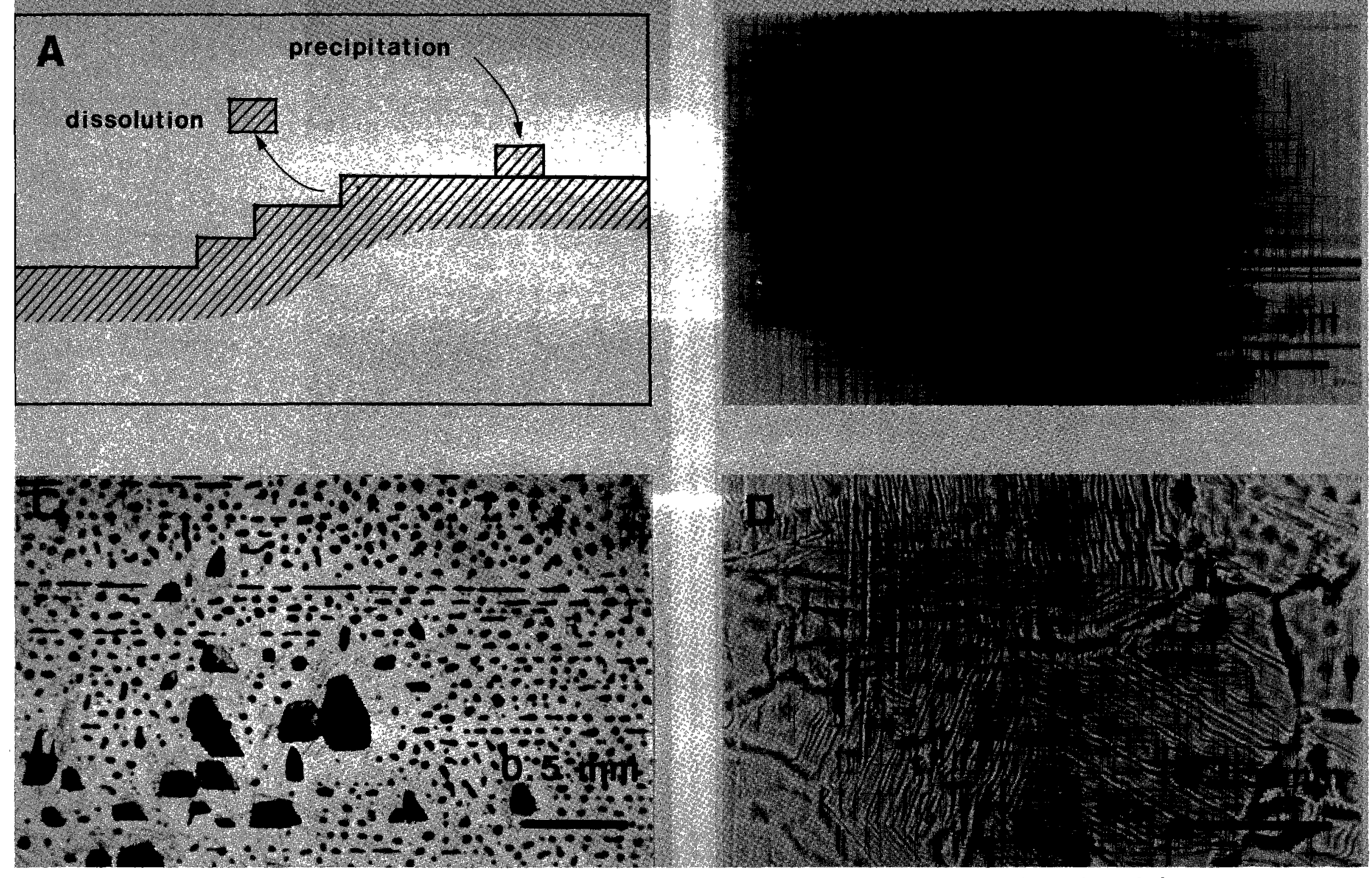

Fig. 3. (a) Dissolution and redeposition features on the surfaces of hydrothermally annealed quartz crystals. (b) Optical photomicrograph of etched ledges on the $\{0001\}$ surface of sample N-595 $\left(T=900^{\circ} \mathrm{C}, P_{\mathrm{H}} \mathrm{O}=1510 \mathrm{MPa}, t=4.80 \times 10^{3} \mathrm{~s}\right.$ in $\mathrm{H}_{2} \mathrm{O}$ fluid source). (c) Precipitated rhombohedra on the \{0001\} surface of sample N-582 $\left(T=800^{\circ} \mathrm{C}, P_{\mathrm{H}_{2}} \mathrm{O}=1070 \mathrm{MPa}, t=1.73 \times 10^{5} \mathrm{~s}\right.$ in $\mathrm{D}_{2} \mathrm{O}$ fluid source). (d) Dissolved and reprecipitated $\{0001\}$ surface of sample $\mathrm{N}-574\left(T=820^{\circ} \mathrm{C}, P_{\mathrm{H}, \mathrm{O}}\right.$ not well known, $t=1.70 \times 10^{3} \mathrm{~s}$ using talc fluid source) replicating the grain reprecipitated $\{0001\}$ surface of sample $\mathrm{N}-$ of the adjacent $\mathrm{Ag}$ disc.
boundary texture and deformation bands of the 
TABLE 2. Results of Hydrothermal Annealing Experiments

\begin{tabular}{|c|c|c|c|c|c|c|c|c|c|c|c|c|}
\hline \multirow[b]{2}{*}{ Experiment } & \multirow[b]{2}{*}{ Crystal } & \multirow[b]{2}{*}{ Orientation } & \multicolumn{5}{|c|}{ Annealing Conditions } & \multicolumn{4}{|c|}{ Results of IR Measurements at $T=25^{\circ} \mathrm{C}$} & \multirow[b]{2}{*}{ Comment } \\
\hline & & & ${ }^{T} \mathrm{C}$ & $\begin{array}{c}P_{c} \\
\mathrm{MPa}\end{array}$ & $\begin{array}{l}P_{\mathrm{H}_{2} \mathrm{O}} \\
\mathrm{MPa}\end{array}$ & $\begin{array}{l}t, \\
\mathrm{~s}\end{array}$ & $\begin{array}{c}\text { Fluid } \\
\text { Source }^{a}\end{array}$ & $\begin{array}{c}\alpha^{b} \\
\mathrm{~mm}^{-1}\end{array}$ & $\begin{array}{c}v, \\
m^{-1}\end{array}$ & $\underset{\mathrm{mm}^{-2}}{\Delta)^{c}}$ & $C\left(\mathrm{H} / 10^{6} \mathrm{Si}\right)$ & \\
\hline $\begin{array}{l}\text { Quartz } \\
\text { starting } \\
\text { material }\end{array}$ & $\begin{array}{r}\text { Brazil } \\
\text { A-1 }\end{array}$ & $\| c$ & $\cdots$ & $\cdots$ & $\cdots$ & $\cdots$ & $\cdots$ & 0.031 & 337.7 & 0.42 & 34 & \\
\hline $\begin{array}{l}\text { Quartz } \\
\text { starting } \\
\text { material }\end{array}$ & $\begin{array}{l}\text { Switzerland } \\
\text { Q-37 }\end{array}$ & $\| c$ & $\cdots$ & $\cdots$ & $\cdots$ & $\cdots$ & $\cdots$ & 0.096 & 337.7 & 1.18 & 96 & \\
\hline $\mathrm{N}-557$ & A-1 & $\| c$ & 700 & 1490 & 400 & $9.27 \times 10^{5}$ & $\mathbf{M}$ & 0.077 & 337.7 & 0.87 & 71 & \\
\hline N-597 & A-1 & $\| c$ & 700 & 1540 & 1540 & $7.57 \times 10^{4}$ & $\mathrm{H}$ & 0.027 & 337.7 & 0.67 & 54 & \\
\hline N-563 & A-1 & $\| c$ & 800 & 1020 & 890 & $9.18 \times 10^{3}$ & $\mathbf{M}$ & 0.037 & 337.7 & 0.52 & 42 & \\
\hline N-569 & A-1 & $\| c$ & 800 & 1050 & 890 & $2.21 \times 10^{4}$ & $\mathbf{M}$ & 0.070 & 337.7 & 0.85 & 69 & \\
\hline N-561 & A-1 & $\| c$ & 800 & 980 & 890 & $1.74 \times 10^{5}$ & $\mathbf{M}$ & 0.107 & 337.7 & 1.12 & 91 & \\
\hline N-560 & A-1 & $\| c$ & 800 & 1500 & & $1.75 \times 10^{5}$ & $\mathbf{M}$ & 0.030 & 337.7 & & & $\begin{array}{l}\text { fluid communica- } \\
\text { tion problems }\end{array}$ \\
\hline N-556 & A-1 & $\| c$ & 800 & 1540 & 890 & $1.77 \times 10^{5}$ & $\mathbf{M}$ & $\begin{array}{c}0.087 \\
(\mathbf{E} \perp c) \\
0.010 \\
(\mathbf{E} \| c)\end{array}$ & $\begin{array}{l}337.7 \\
337.7\end{array}$ & 0.88 & 72 & \\
\hline N-562 & A-1 & $\| c$ & 800 & 1000 & 890 & $1.90 \times 10^{5}$ & $\mathbf{M}$ & 0.069 & 337.7 & 1.01 & 82 & \\
\hline N-581 & A-1 & $\| c$ & 800 & 1080 & 890 & $6.04 \times 10^{5}$ & $\mathbf{M}$ & 0.106 & 337.7 & 0.99 & 80 & \\
\hline N-579 & A-1 & $\perp c$ & 800 & 1100 & 890 & $1.45 \times 10^{4}$ & $\mathbf{M}$ & 0.015 & 337.7 & 0.69 & 56 & \\
\hline N-591 & A-1 & $\perp c$ & 800 & 1130 & 890 & $1.46 \times 10^{4}$ & $\mathbf{M}$ & 0.014 & 337.7 & 0.28 & 23 & \\
\hline N-585 & Q-37 & $\| c$ & 800 & 1150 & 890 & $1.74 \times 10^{5}$ & $\mathbf{M}$ & 0.247 & 337.7 & 2.23 & 181 & \\
\hline N-583 & A-1 & $\| c$ & 800 & 1550 & 1550 & $1.73 \times 10^{5}$ & C & 0.074 & 337.7 & 0.74 & 60 & \\
\hline N-570 & A-1 & $\| c$ & 800 & 1530 & 1530 & $1.75 \times 10^{5}$ & $\mathrm{H}$ & 0.073 & 337.7 & 0.88 & 71 & \\
\hline N-582 & A-1 & $\| c$ & 800 & 1070 & 1070 & $1.73 \times 10^{5}$ & D & 0.070 & 250.3 & & & \\
\hline N-598 & A-1 & $\| c$ & 800 & 1100 & 1100 & $3.80 \times 10^{5}$ & 018 & 0.077 & 337.7 & 0.79 & 64 & \\
\hline N-586 & A-1 & $\| \boldsymbol{c}$ & 800 & 1120 & 1120 & $1.73 \times 10^{5}$ & $0.1 \mathrm{~N}$ & 0.077 & 337.7 & 0.92 & 75 & \\
\hline N-590 & A-1 & $\| c$ & 800 & 1150 & 1150 & $1.73 \times 10^{5}$ & $1.0 \mathrm{~N}$ & 0.053 & 337.7 & 0.89 & 72 & \\
\hline N-574 & A-1 & $\| c$ & 820 & 1550 & & $1.70 \times 10^{5}$ & $T$ & 0.075 & 337.7 & 0.72 & 58 & \\
\hline N-554 & A-1 & $\| \boldsymbol{c}$ & 850 & 970 & & $3.57 \times 10^{5}$ & TA & 0.063 & 337.7 & 1.19 & 97 & microcracks \\
\hline N-577 & A-1 & $\| c$ & 850 & 1560 & & $1.78 \times 10^{5}$ & TA & 0.108 & 337.7 & 1.07 & 87 & \\
\hline N-589 & A-1 & $0^{+}$ & 850 & 1520 & & $4.39 \times 10^{5}$ & $\mathrm{TA}$ & & & & & $\begin{array}{l}\text { microcracks, } \\
\text { basal deforma- } \\
\text { tion lamellae }\end{array}$ \\
\hline N-578 & A-1 & $\| c$ & 900 & 1580 & 1420 & $1.74 \times 10^{5}$ & $\mathbf{M}$ & 0.088 & 337.7 & 0.81 & 66 & \\
\hline $\mathrm{N}-609$ & A-1 & $\| c$ & 900 & 1550 & 1420 & $3.70 \times 10^{6}$ & $\mathbf{M}$ & 0.098 & 337.7 & 1.54 & 125 & microcracks \\
\hline N-595 & A-1 & $\| c$ & 900 & 1510 & 1510 & $4.80 \times 10^{3}$ & $\mathbf{H}$ & 0.074 & 337.7 & 0.92 & 74 & \\
\hline N-613 & A-1 & $\| c$ & 900 & 1550 & 1550 & $3.75 \times 10^{6}$ & $\mathbf{H}$ & 0.123 & 337.7 & 1.21 & 98 & \\
\hline N-604 & A-1 & $\| c$ & 800 & 1150 & 1150 & $2.31 \times 10^{5}$ & $\mathbf{H}$ & 0.053 & 337.7 & 0.55 & 45 & \\
\hline N-620 & A-1 & $\| c$ & 700 & 1180 & 1180 & $5.50 \times 10^{4}$ & D & $\begin{array}{l}0.045 \\
0.042\end{array}$ & $\begin{array}{l}337.7 \\
250.3\end{array}$ & $\begin{array}{l}0.50 \\
0.09\end{array}$ & $\begin{array}{r}41 \\
7\end{array}$ & $\begin{array}{l}\mathrm{N}-604, \\
\text { reannealed }\end{array}$ \\
\hline$N-600$ & A-1 & $\| c$ & 800 & 1090 & 1090 & $1.95 \times 10^{5}$ & $\mathbf{H}$ & 0.061 & 337.7 & 0.68 & 55 & \\
\hline $\mathrm{N}-615$ & A-1 & $\| c$ & 800 & 1090 & 1090 & $1.48 \times 10^{4}$ & D & $\begin{array}{l}0.010 \\
0.053\end{array}$ & $\begin{array}{l}337.7 \\
250.3\end{array}$ & $\begin{array}{l}0.24 \\
0.15\end{array}$ & 19 & $\mathrm{~N}-600$, \\
\hline N-603 & A-1 & $\perp c$ & 800 & 1120 & 1120 & $4.83 \times 10^{5}$ & $\mathbf{H}$ & 0.042 & 337.7 & 0.61 & 50 & \\
\hline N-614 & A-1 & $\perp c$ & 800 & 1070 & 1070 & $1.83 \times 10^{4}$ & D & $\begin{array}{l}0.019 \\
0.028\end{array}$ & $\begin{array}{l}337.7 \\
250.3\end{array}$ & $\begin{array}{l}0.33 \\
0.10\end{array}$ & $\begin{array}{r}27 \\
8\end{array}$ & $\begin{array}{l}\mathrm{N}-603, \\
\text { reannealed }\end{array}$ \\
\hline N-602 & A-1 & $\| c$ & 800 & 1170 & 1170 & $2.26 \times 10^{5}$ & $\mathbf{H}$ & 0.065 & 337.7 & 0.66 & 54 & \\
\hline N-616 & A-1 & $\| c$ & 900 & 1110 & 1110 & $3.90 \times 10^{3}$ & $\mathrm{D}$ & $\begin{array}{l}0.022 \\
0.053\end{array}$ & $\begin{array}{l}337.7 \\
250.3\end{array}$ & $\begin{array}{l}0.39 \\
0.13\end{array}$ & 32 & $\mathrm{~N}-602$, \\
\hline$N-606$ & A-1 & $\perp c$ & 800 & 1090 & 1090 & $4.05 \times 10^{5}$ & $\mathbf{H}$ & 0.030 & 337.7 & 0.52 & 42 & \\
\hline N-621 & A-1 & $\perp c$ & 900 & 1130 & 1130 & $4.44 \times 10^{3}$ & D & $\begin{array}{l}0.014 \\
0.041\end{array}$ & $\begin{array}{l}337.7 \\
250.3\end{array}$ & $\begin{array}{l}0.30 \\
0.16\end{array}$ & $\begin{array}{l}24 \\
13\end{array}$ & $\begin{array}{l}\mathrm{N}-606, \\
\text { reannealed }\end{array}$ \\
\hline
\end{tabular}

${ }^{a}$ Fluid source: $\mathrm{M}, \mathrm{Mg}(\mathrm{OH})_{2}+\mathrm{MgO}+\mathrm{H}_{2} \mathrm{O}$ (in Au capsule); $\mathrm{C}, \mathrm{Cu}+\mathrm{Cu}_{2} \mathrm{O}+\mathrm{H}_{2} \mathrm{O}$ (in Au capsule); $\mathrm{H}, \mathrm{H}_{2} \mathrm{O}$ (in Au capsule); $\mathrm{D}, \mathrm{D} 2 \mathrm{O}$ (in Au capsule); $018, \mathrm{H}_{2}{ }^{18} \mathrm{O}$ (in Au capsule); $N, N$ NaOH solution (in Au capsule); T, talc (in Au capsule); and TA, talc assembly (no jacket).

${ }^{b}$ Absorption coefficient $\alpha$ measured at selected wave number $v$.

${ }^{c}$ Integral absorption $\Delta$ measured over wave numbers of $300-365 \mathrm{~mm}^{-1}$ for O-H, 245-265 $\mathrm{mm}^{-1}$ for O-D.

and Mackwell and Paterson [1985] was affected by microcracking.

\section{EXPERIMENTAL MeThODS}

\section{Starting Materials}

All quartz samples for this study, except one, were taken from the same optical grade, Brazilian single crystal (A-1) as used by Griggs and Blacic [1964, 1965] in their discovery experiments. Its initial hydrogen concentration of $35 \pm 10$ ppm $\left(\mathrm{H} / 10^{6} \mathrm{Si}\right)$ was determined by IR spectroscopy. Other trace element impurity concentrations (Table 1) were determined by quantitative emission spectroscopy and flame photometry. Optical observations showed little evidence of inclusions and chemical etching of original growth faces revealed only widely spaced Dauphiné twin boundaries.

One additional quartz sample was prepared from a colorless Swiss single crystal (Q-37 [Bambauer, 1961]) rich in aluminum (Table 1), in order to test for the association of hydrogen and aluminum impurities. 
TABLE 3. IR Absorption Band Assignments

\begin{tabular}{|c|c|c|c|c|c|}
\hline \multirow{2}{*}{$\begin{array}{c}\text { Brazilian } \\
\text { Quartz } \\
\text { Crystal } \\
\text { A-1 }\end{array}$} & \multirow{2}{*}{$\begin{array}{c}\text { Swiss } \\
\text { Quartz } \\
\text { Crystal } \\
\text { Q-37 }\end{array}$} & \multicolumn{2}{|c|}{$\begin{array}{l}\text { Hydrothermally } \\
\text { Annealed Crystal }\end{array}$} & \multirow{2}{*}{$\begin{array}{c}\text { O-H Absorption } \\
\text { Bands Identified } \\
\text { by Kats } \\
{[1962]}\end{array}$} & \multirow{2}{*}{$\begin{array}{c}\text { Growth }(+) \text { or } \\
\text { Decrease }(-) \text { at } \\
T=800^{\circ} \mathrm{C} \\
P_{\mathrm{H}_{2} \mathrm{O}}=890 \mathrm{MPa}\end{array}$} \\
\hline & & A-1 & Q-37 & & \\
\hline 320.0 & 320.0 & 320.0 & 320.0 & 320.5 & unchanged \\
\hline 330.3 & 330.3 & 330.3 & 330.0 & $330.5 \mathrm{H}$ & $(+)$ \\
\hline $336.4^{a}$ & 336.4 & 336.4 & 336.4 & 337.1 H (associated Al) & $(+)$ \\
\hline$\cdots$ & 339.1 & $\cdots$ & 339.1 & 339.6 H (associated Li) & $(-)$ \\
\hline$\cdots$ & 342.4 & $\cdots$ & $\ldots$ & $342.2 \mathrm{H}$ & $(-)$ \\
\hline $342.8^{a}$ & $\cdots$ & 342.8 & 342.8 & 343.5 H (associated Al) & $(+)$ \\
\hline$\cdots$ & 343.3 & & & $344.0 \mathrm{H}$ (associated Li) & $(-)$ \\
\hline 346.4 & 346.4 & 346.4 & 346.4 & $346.2 \mathrm{H}$ & $(+,-)$ \\
\hline 347.2 & 347.2 & 347.2 & 347.2 & 347,0 & $(-)$ \\
\hline & 350.2 & $\ldots$ & $\cdots$ & $351.0 \mathrm{H}$ (associated Li) & $(-)$ \\
\hline$\cdots$ & 351.4 & $\cdots$ & $\cdots$ & $352.0 \mathrm{H}$ (associated Li) & $(-)$ \\
\hline$\cdots$ & & $\cdots$ & 357.7 & $357.8 \mathrm{H}$ (associated $\mathrm{K})$ & $i+j$ \\
\hline 359.2 & 359.2 & 359.2 & 359.2 & $359.0 \mathrm{H}$ & $(+)$ \\
\hline
\end{tabular}

Wave number $v\left(\mathrm{~mm}^{-1}\right)$ at $T=77 \mathrm{~K}$.

${ }^{a}$ Principle absorption bands in bold face.

\section{Hydrothermal Anneals}

Cylindrical samples $(6.3 \mathrm{~mm}$ in diameter and $\sim 3 \mathrm{~mm}$ in length) were cored in two orientations: (1) parallel and (2) perpendicular to the $c$ axis of each crystal and their ends ground parallel (manually on glass plates) and polished (using a rotary lap) using $\mathrm{Al}_{2} \mathrm{O}_{3}$ and $\mathrm{Ce}_{2} \mathrm{O}_{3}$ with grit sizes down to $0.3 \mu \mathrm{m}$. With the exception of three samples annealed in conventional talc assemblies (similar to those of Griggs and Blacic [1965]), all samples were sealed (Figure 2) in Au capsules (using standard carbon arc-welding techniques) with one of the following fluid sources: (1) $5 \mu \mathrm{L} \mathrm{H}_{2} \mathrm{O}+\mathrm{Mg}(\mathrm{OH})_{2}+$ $\mathrm{MgO}$, (2) $10 \mu \mathrm{L} \mathrm{H}_{2} \mathrm{O}+\mathrm{Cu}+\mathrm{Cu}_{2} \mathrm{O}$, (3) $10 \mu \mathrm{L} \mathrm{H}_{2} \mathrm{O}$ (isotopically normal), $\mathrm{D}_{2} \mathrm{O}(99.8$ atom $\% \mathrm{D} / \mathrm{H})$, and $\mathrm{H}_{2}{ }^{18} \mathrm{O}(98.4$ atom $\%{ }^{18} \mathrm{O} /{ }^{16} \mathrm{O}$ ), (4) $10 \mu \mathrm{L} 0.1 \mathrm{~N} \mathrm{NaOH}$ solution and $1.0 \mathrm{~N}$ $\mathrm{NaOH}$ solution, and (5) talc. Beveled $\mathrm{Ag}$ discs were included to prevent puncturing of the Au jacket (wall thickness of 0.25 $\mathrm{mm}$ ) by the sharp edges of the quartz crystals. In addition, granular $\mathrm{SiO}_{2}$ (either in the form of crystalline powder or a disc of porous quartzite) was placed between the fluid source and the sample in those experiments using the $\mathrm{Mg}(\mathrm{OH})_{2}+$ $\mathrm{MgO}+\mathrm{H}_{2} \mathrm{O}$ fluid source, in order to prevent reaction to enstatite (i.e., by reducing the $\mathrm{MgO}$ activity and increasing the $\mathrm{SiO}_{2}$ activity in the fluid prior to contact with sample).

The sealed Au capsules were then placed at the centers of $\mathrm{NaCl}$ piston-cylinder assemblies described earlier [Kirby and Kronenberg, 1984a], substituting the ceramic pistons (used in deformation experiments) with pressed $\mathrm{NaCl}$ plugs and packed granular $\mathrm{NaCl}$, and annealed at temperatures of $700^{\circ}-$ $900^{\circ} \mathrm{C}$ and pressures of $400-1580 \mathrm{MPa}$ using a Griggs apparatus. A confining pressure of $150 \mathrm{MPa}$ was applied (over a period of $\sim 3-5$ hours) prior to raising the temperature to $100^{\circ} \mathrm{C}$, and the pressure and temperature were raised stepwise to $250 \mathrm{MPa}$ and $300^{\circ} \mathrm{C}$, respectively, in such a way as to keep the specific volume of water within the Au jacket below $\sim 1.1$. The presure was then increased smoothly over a period of $\sim 10$ hours (using a small volume hydraulic pump) in order to prevent the development of significant nonhydrostatic stresses, and the temperature was then raised to the desired experimental conditions. Confining pressures were released gradually ( $\sim 1$ hour) following annealing. We believe that these slow changes in pressure were important to prevent microcracking, allowing us to retrieve samples which were, with some exceptions, crack-free.

Most of the annealing experiments were done using a mix- ture of brucite, periclase, and distilled $\mathrm{H}_{2} \mathrm{O}$ as the fluid source (the first listed above) in order to control the water pressure $P_{\mathrm{H}_{2} \mathrm{O}}$ inside the Au jacket. The univariant dehydration reaction

$$
\mathrm{Mg}(\mathrm{OH})_{2} \rightleftharpoons \mathrm{MgO}+\mathrm{H}_{2} \mathrm{O}
$$

has been investigated by a number of techniques over a wide range of pressure and temperature, and its reaction kinetics are known to be rapid [Barnes and Ernst, 1963; Weber and Roy, 1965; Yamaoka et al., 1970; Irving et al., 1977; Schramke et al., 1982]. Equilibrium between all three phases therefore buffers the water pressure directly for any given temperature (i.e., $P_{\mathrm{H}_{2} \mathrm{O}}=890 \mathrm{MPa}$ at $T=800^{\circ} \mathrm{C}$ ); the presence of $\mathrm{Mg}(\mathrm{OH})_{2}$ and $\mathrm{MgO}$ in the solid powder mixtures was tested routinely after each experiment by $\mathrm{X}$ ray diffraction methods (Figure 2c).

A mixture of $\mathrm{Cu}, \mathrm{Cu}_{2} \mathrm{O}$, and $\mathrm{H}_{2} \mathrm{O}$ was used to buffer the $P_{\mathrm{O}_{2}}$ directly [Huebner, 1971; Swalin, 1972] in one annealing experiment. A variety of other fluid sources, including distilled $\mathrm{H}_{2} \mathrm{O}, \mathrm{NaOH}$ solutions, and talc were used to reproduce the chemical environments of previous studies of quartz defor-

TABLE 4. Chemical Analyses of Hydrothermally Annealed, Brazilian Quartz Crystals

\begin{tabular}{cccc}
\hline $\begin{array}{c}\text { Trace } \\
\text { Element }\end{array}$ & $\begin{array}{c}\text { Crystal A-1 } \\
\text { Starting Material, } \\
\text { atom ppm/Si }\end{array}$ & $\begin{array}{c}\text { Annealed A-1 } \\
\text { Crystals, } \\
\text { atom ppm/Si }\end{array}$ & $\begin{array}{c}\text { Growth (+) } \\
\text { or decrease }(-) \\
\text { at } T=800^{\circ} \mathrm{C} \text { and } \\
P_{\mathbf{H}_{2} \mathbf{O}}=890 \mathrm{MPa}\end{array}$ \\
\hline $\mathbf{H}$ & $35 \pm 10^{a}$ & $83 \pm 10^{\mathrm{a}}$ & $(+)$ \\
$\mathrm{Li}$ & $40^{b}$ & $<17^{b}$ & $(-)$ \\
$\mathrm{Na}$ & $150^{c}$ & $<100^{c}$ & $(-)$ \\
$\mathrm{K}$ & $19^{c}$ & $<13^{c}$ & $(-)$ \\
$\mathrm{Mg}$ & $7^{b}$ & $105^{b}$ & $(+)$ \\
$\mathrm{Cr}$ & $<6^{b}$ & $<6^{b}$ & \\
$\mathrm{Mn}$ & $<1^{b}$ & $<1^{b}$ & \\
$\mathrm{Fe}$ & $16 \pm 2^{b}$ & $5 \pm 5^{b}$ & \\
$\mathrm{Al}$ & $91 \pm 1^{b}$ & $67 \pm 35^{b}$ & \\
\hline
\end{tabular}

${ }^{a}$ Analysis by infrared spectroscopy, present study.

${ }^{b}$ Quantitative emission spectroscopy (Dc arc or inductively coupled plasma excitation). P. Klock and T. Fries, analysts, U.S. Geological Survey, Menlo Park.

${ }^{c}$ Quantitative flame photometry. P. Klock, analyst, U.S. Geological Survey, Menlo Park. 
TABLE 5. Diffusion Coefficients for $\mathbf{H}$ Interstitials in Quartz

\begin{tabular}{|c|c|c|c|c|}
\hline \multirow{3}{*}{${ }^{T} \mathrm{C}$} & \multicolumn{4}{|c|}{$\mathrm{D}, \mathrm{m}^{2} / \mathrm{s}$} \\
\hline & \multicolumn{2}{|c|}{ Based Upon H Uptake } & \multicolumn{2}{|c|}{ Based Upon H-D Exchange } \\
\hline & $\| c$ & $\perp c$ & $\| c$ & $\perp c$ \\
\hline 700 & $\begin{array}{c}(3 \pm 2.7) \times 10^{-12} \\
(\mathrm{~N}-597)\end{array}$ & $\cdots$ & $\begin{array}{c}(6 \pm 4.6) \times 10^{-13} \\
(\mathrm{~N}-620)\end{array}$ & $\cdots$ \\
\hline 800 & $\begin{array}{c}(2 \pm 1.6) \times 10^{-11} \\
(\mathrm{~N}-563) \\
(\mathrm{N}-569)\end{array}$ & $\left(2 \pm \frac{1.5) \times 10^{-11}}{(\mathrm{~N}-579)}\right.$ & $\begin{array}{c}(3 \pm 2.1) \times 10^{-11} \\
(\mathrm{~N}-615)\end{array}$ & $\begin{array}{c}(9 \pm 7.5) \times 10^{-12} \\
(\mathrm{~N}-614)\end{array}$ \\
\hline 900 & $\begin{array}{c}(2 \pm 1.8) \times 10^{-10} \\
(\mathrm{~N}-595)\end{array}$ & $\cdots$ & $\left(5 \pm \frac{3.8) \times 10^{-11}}{(\mathrm{~N}-616)}\right.$ & $\begin{array}{c}(4 \pm 3.4) \times 10^{-11} \\
(\mathrm{~N}-621)\end{array}$ \\
\hline
\end{tabular}

mation and crystal growth. The $P_{\mathrm{H}_{2} \mathrm{O}}$ in these experiments was assumed to equal the applied confining pressure $P_{c}$; the presence of fluid was evident upon puncturing the $\mathrm{Au}$ jackets in experiments using $\mathrm{H}_{2} \mathrm{O}$ and $\mathrm{NaOH}$ solutions and from coloration due to dehydration in experiments using talc.

The solubility of $\mathrm{SiO}_{2}$ in $\mathrm{H}_{2} \mathrm{O}$ at the experimental conditions [Anderson and Burnham, 1965] is large (>6 wt \% at $T=800^{\circ} \mathrm{C}$ and $P_{\mathrm{H}_{2} \mathrm{O}}=890 \mathrm{MPa}$ ), and sample surfaces exhibit evidence of dissolution and redeposition (Figure 3) in the form of etched ledges and precipitated rhombohedrons; in addition, annealed quartz surfaces often replicated the grain boundary textures and deformation bands of the adjacent $\mathrm{Ag}$ discs. Solution-related surface modification was minimized, however, in those experiments using the $\mathrm{Mg}(\mathrm{OH})_{2}+\mathrm{MgO}+\mathrm{H}_{2} \mathrm{O}$ fluid source by applying an external confining pressure $\boldsymbol{P}_{\boldsymbol{c}}$ slightly in excess of the equilibrium $\boldsymbol{P}_{\mathbf{H}_{2} \mathbf{O}}$ and thereby limiting the volume of liquid $\mathrm{H}_{2} \mathrm{O}$ to $<5 \mu \mathrm{L}$. Secondary ion microprobe analyses of ${ }^{27} \mathrm{Al}$ and ${ }^{28} \mathrm{Si}$ for these surfaces (P. F. Dennis and B. J. Giletti, personal communication, 1984) show that surface modification was restricted to the top $1 \mu \mathrm{m}$. Dissolution steps and precipitation features are more pronounced on samples annealed in $10 \mu \mathrm{L} \mathrm{H}_{2} \mathrm{O}$, and the surfaces of samples annealed in $\mathrm{NaOH}$ solutions are badly frosted. These surface features indicate that the fluids were in chemical communication with the quartz samples.

\section{Deformation Experiments}

Constant strain rate experiments were conducted on cylindrical (5.8 and $6.3 \mathrm{~mm}$ in diameter and $16.5 \mathrm{~mm}$ in length) Brazilian quartz samples in the $\mathrm{O}^{+}$orientation $\left(\sigma_{1}\right.$ direction at $45^{\circ}$ to $a$ and $c$ ) under dry conditions and under hydrothermal conditions similar to those of the annealing experiments. The dry strength of quartz was tested for samples placed in $\mathrm{Au}$ jackets and end-loaded using ceramic $\left(0.9 \mathrm{Al}_{2} \mathrm{O}_{3}\right.$ $: 0.1 \mathrm{TiO}$ ) pistons in $\mathrm{NaCl}$ solid-medium assemblies (experimental methods and uncertainties discussed by Kirby and Kronenberg [1984a]). The strength of hydrothermally annealed quartz was likewise measured using $\mathrm{NaCl}$ assemblies; however, samples were sealed in Au jackets (by arc-welding specially fitted Au caps to the ends of the Au jackets) with a mixture of $\mathrm{Mg}(\mathrm{OH})_{2}+\mathrm{MgO}+\mathrm{H}_{2} \mathrm{O}$ packed along the samples' cylindrical sides. Although we applied external confining pressures $P_{c}$ of $\sim 1500 \mathrm{MPa}$ during these experiments, we expect that the internal $P_{\mathrm{H}_{2} \mathrm{O}}$ was still controlled by the $\mathrm{Mg}(\mathrm{OH})_{2}+\mathrm{MgO}+\mathrm{H}_{2} \mathrm{O}$ buffer yielding an effective contining pressure $P_{e}$ of $\sim 600 \mathrm{MPa}$ at $T=800^{\circ} \mathrm{C}$, where $P_{e}$ is given by $P_{c}-P_{\mathrm{H}_{2} \mathrm{O}}$. Accepting that this assumption, that $\boldsymbol{P}_{c} \neq \boldsymbol{P}_{\text {total fluid }}$, is uncommon in studies of phase equilibria, the concept of effective pressure has been widely applied in rock mechanics studies [e.g., Hubbert and Willis, 1957; Hubbert and

TABLE 6. Results of Deformation Experiments

\begin{tabular}{|c|c|c|c|c|c|c|c|c|c|c|c|c|}
\hline \multirow[b]{2}{*}{ Experiment } & \multirow[b]{2}{*}{ Crystal } & \multirow[b]{2}{*}{ Orientation } & \multicolumn{5}{|c|}{ Hydrostatic Annealing Conditions } & \multicolumn{4}{|c|}{ Deformation Conditions } & \multirow[b]{2}{*}{ Comment } \\
\hline & & & $\begin{array}{l}T, \\
{ }^{\circ} \mathrm{C}\end{array}$ & $\begin{array}{l}\boldsymbol{P}_{\mathrm{c}}, \\
\mathbf{M P a}\end{array}$ & $\begin{array}{l}P_{\mathrm{H}_{2} \mathrm{O}} \\
\mathbf{M P a}\end{array}$ & $\begin{array}{l}t \\
\mathrm{~s}\end{array}$ & $\begin{array}{l}\text { Fluid } \\
\text { Source }^{a}\end{array}$ & $\begin{array}{l}T, \\
{ }^{\circ} \mathrm{C}\end{array}$ & $\mathbf{s}^{-1}$ & $\begin{array}{l}\varepsilon, \\
\%\end{array}$ & $\begin{array}{l}\sigma^{b} \\
\mathrm{MPa}\end{array}$ & \\
\hline N-594 & A-1 & $0^{+}$ & 800 & 600 & $\sim 0$ & $6.90 \times 10^{4}$ & none & 800 & $1.0 \times 10^{-5}$ & 2.5 & 2880 & $\begin{array}{l}\text { elastic slope to fracture, } \\
\text { sharp macroscopic fault, } \\
\text { no plastic yielding }\end{array}$ \\
\hline $\mathrm{N}-565$ & A-1 & $0^{+}$ & 800 & 1490 & $\sim 0$ & $1.39 \times 10^{5}$ & none & 800 & $1.0 \times 10^{-5}$ & 12.2 & 3110 & $\begin{array}{l}\text { dense microcracks, } \\
\text { undulatory extinction }\end{array}$ \\
\hline N-576 & A-1 & $0^{+}$ & 800 & 1600 & 890 & $1.70 \times 10^{5}$ & $\mathbf{M}$ & 800 & $1.0 \times 10^{-5}$ & 4.4 & 3020 & $\begin{array}{l}\text { dense microcracks, } \\
\text { unduiatory extinction }\end{array}$ \\
\hline$N-567$ & A-1 & $0^{+}$ & 800 & 1570 & 890 & $1.75 \times 10^{5}$ & $\mathbf{M}$ & 800 & $1.0 \times 10^{-5}$ & 8.9 & 2350 & $\begin{array}{l}\text { recrystallized grains } \\
\text { along microcracks }\end{array}$ \\
\hline N-568 & A-1 & $0^{+}$ & 800 & 1580 & 890 & $2.21 \times 10^{5}$ & $\mathbf{M}$ & 800 & $1.0 \times 10^{-5}$ & 4.6 & 1360 & $\begin{array}{l}\text { dense microcracks, } \\
\text { undulatory extinction }\end{array}$ \\
\hline N-588 & A-1 & $0^{+}$ & 850 & 1480 & & $3.96 \times 10^{4}$ & TA & 800 & $1.0 \times 10^{-5}$ & 19.5 & 970 & $\begin{array}{l}\text { dense microcracks, } \\
\text { fluid inclusions } \\
\text { basal + prismatic } \\
\text { deformation lamellae }\end{array}$ \\
\hline N-584 & A-1 & $0^{+}$ & 850 & 1480 & & $3.53 \times 10^{5}$ & $\mathbf{T A}$ & 800 & $1.0 \times 10^{-5}$ & 2.3 & 2530 & $\begin{array}{l}\text { microcracks, } \\
\text { macroscopic fault }\end{array}$ \\
\hline N-587 & A-1 & $0^{+}$ & 850 & 1500 & & $4.03 \times 10^{5}$ & $\mathbf{T A}$ & 800 & $1.0 \times 10^{-5}$ & 11.0 & 2570 & $\begin{array}{l}\text { microcracks, } \\
\text { undulatory extinction }\end{array}$ \\
\hline
\end{tabular}

${ }^{o}$ Fluid source: $\mathrm{M}, \mathrm{Mg}(\mathrm{OH})_{2}+\mathrm{MgO}+\mathrm{H}_{2} \mathrm{O}$ (in Au capsule); and TA, talc assembly (no jacket).

${ }^{b}$ Maximum recorded deviatoric stress. 
Rubey, 1959; Handin et al., 1963; Brace and Martin, 1968] as that portion of the confining pressure supported by a porous solid. The persistence of open pore space (wherein $P_{\text {total fluid }}$ may be less than $P_{c}$ ) within the Au jackets is suggested by the lack of adhesion of $\mathrm{Au}$ to sample surfaces and the porous nature of the $\mathrm{Mg}(\mathrm{OH})_{2}+\mathrm{MgO}$ mixtures following annealing and deformation experiments. Therefore rather than assuming that the reaction $\mathrm{Mg}(\mathrm{OH})_{2} \rightleftharpoons \mathrm{MgO}+\mathrm{H}_{2} \mathrm{O}$, which is known to be rapid, was out of equilibrium, we treat the effective pressure $P_{e}$ as a "partial pressure" of the solid phases [Fyfe et al., 1978, p. 135].

In addition to these constant strain rate experiments using $\mathrm{NaCl}$ assemblies, we repeated mechanical tests of unjacketed Brazilian quartz samples using conventional talc assemblies after annealing (in talc) for times of $4 \times 10^{4}$ and $4 \times 10^{5} \mathrm{~s}$. Because the kinetics of the dehydration reactions talc $\rightarrow$ anthophyllite + quartz $+\mathrm{H}_{2} \mathrm{O}$ and anthophyllite $\rightarrow$ enstatite + quartz $+\mathrm{H}_{2} \mathrm{O}$ are relatively slow [e.g., Greenwood, 1963], we expect that the $P_{\mathrm{H}_{2} \mathrm{O}}$, and thus $P_{e}$, must vary with time for these experiments. In addition, as a result of the fluid's contact with the carbon furnace [French, 1966] and temperature gradients within the sample assembly, we cannot be certain of the values of $P_{\mathrm{H}_{2} \mathrm{O}}, P_{\mathrm{CH}_{4}}, P_{\mathrm{CO}}, P_{\mathrm{CO}_{2}}$, or $P_{\mathrm{O}_{2}}$ for these experiments.

\section{Infrared Spectroscopy}

Infrared (IR) absorption spectra of hydrothermally annealed samples were measured over the range in wave number $v$ from 200 to $400 \mathrm{~mm}^{-1}$ [Alpert et al., 1970; Aines and Rossman, 1984] using a Perkin-Elmer 180 spectrophotometer interfaced with a DEC PDP11 minicomputer. Most of the IR spectra were obtained from the central regions of samples (through apertures $1-3 \mathrm{~mm}$ in diameter) using an unpolarized incident beam parallel to the $c$ axis. Polarized IR spectra were also measured for selected samples using an IR polarizer (gold wire on $\mathrm{AgBr}$ substrate) and incident beam perpendicular to $c$ with $\mathbf{E} \perp c$ and $\mathbf{E} \| c$, respectively. Absorption bands were separat-

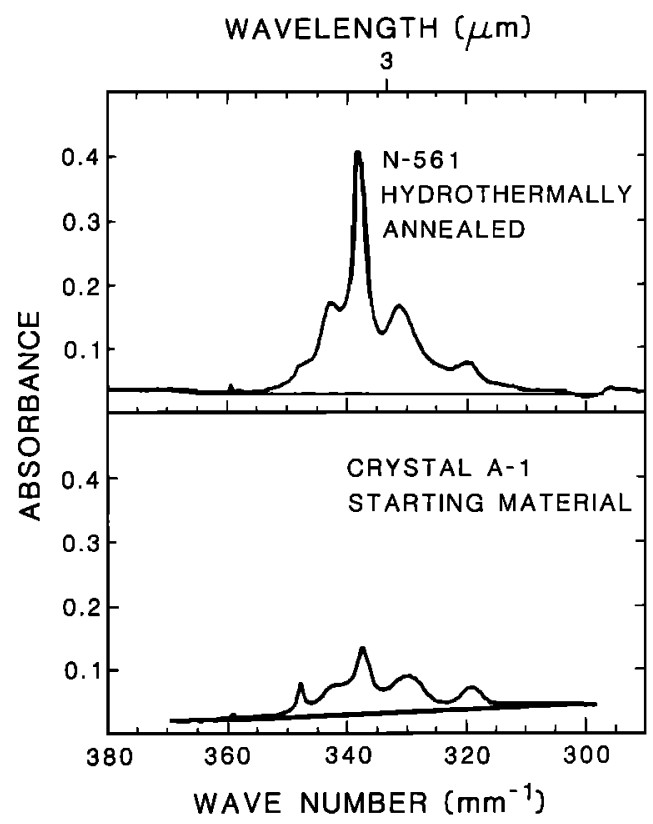

Fig. 4. IR absorption spectra of Brazilian quartz, crystal A-1, before (A-1) and after (N-561) annealing at $T=800^{\circ} \mathrm{C}, P_{\mathrm{H}_{2} \mathrm{O}}=890$ $\mathrm{MPa}, t=1.74 \times 10^{5} \mathrm{~s}$ (spectra measured at room temperature using unpolarized IR beam parallel to $c$, sample thicknesses $L=3.26$ and $3.29 \mathrm{~mm}$ for A-1 and N-561, respectively).

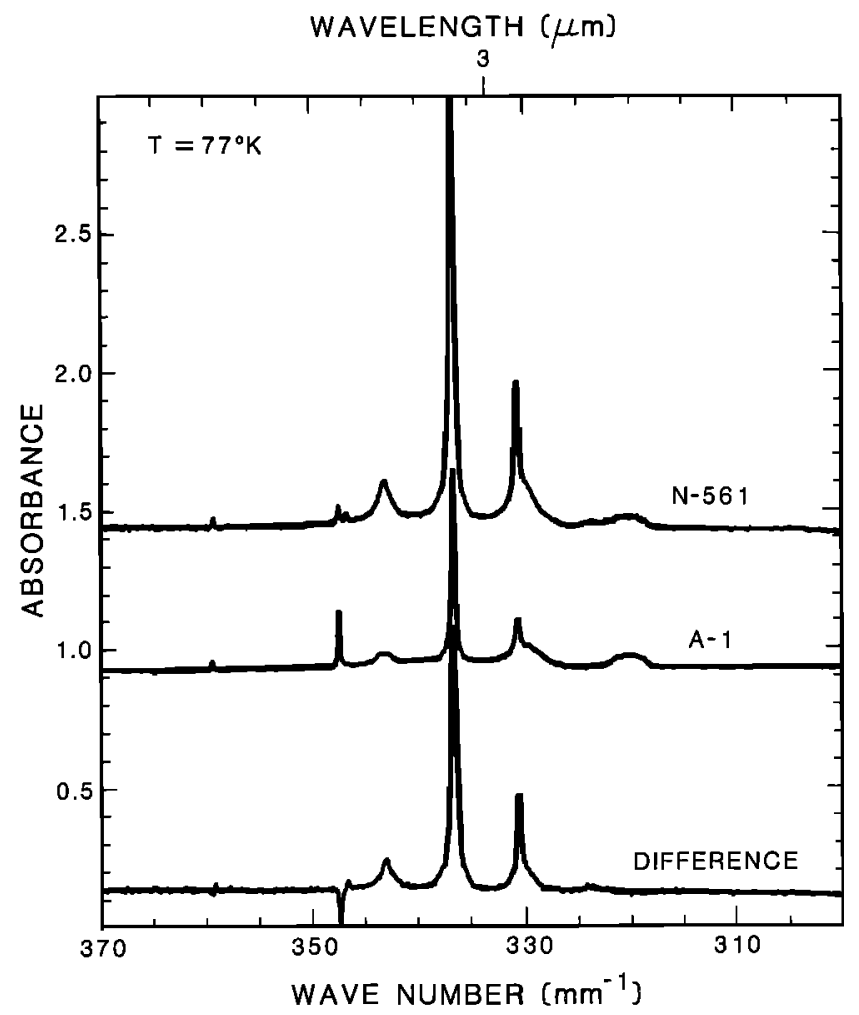

Fig. 5. IR absorption spectra of Brazilian quartz starting material (A-1) and annealed crystal N-561 $\left(T=800^{\circ} \mathrm{C}, P_{\mathrm{H}_{2} \mathrm{O}}=890 \mathrm{MPa}, t=\right.$ $\left.1.74 \times 10^{5} \mathrm{~s}\right)$ measured at hquid $\mathrm{N}_{2}$ temperature $(77 \mathrm{~K})$. Difference spectrum (determined by subtracting spectrum of A-1 from that of $\mathrm{N}-561)$ reveals the uptake of $\mathrm{O}-\mathrm{H}$ defects by positive deflections, whereas unstable defects are indicated by negative deflections (unpolarized IR beam parallel to $c, L=3.26$ and $3.29 \mathrm{~mm}$ for A-1 and $\mathrm{N}-561$, respectively).

ed and identified in spectral measurements at $\sim 77 \mathrm{~K}$ (using liquid $\mathrm{N}_{2}$ and an evacuated dewar with $\mathrm{KBr}$ windows), and absorption band peak heights and integral absorptions were determined from room temperature spectra. The slit width of low-temperature $(77 \mathrm{~K})$ measurements was chosen so as to yield a wave number resolution of $0.2 \mathrm{~mm}^{-1}$. Peak height and integral absorption measurements were made at room temperature by subtracting a linear baseline (fit to background values at $\sim 300$ and $\sim 365 \mathrm{~mm}^{-1}$ ). The estimated error in this procedure is $5-10 \%$. Hydrogen concentration determinations were made using the integral absorbances $\Delta$ and the calibration factor of $0.812\left(\mathrm{~cm}^{2} \mathrm{H} / 10^{6} \mathrm{Si}\right)$ reported by Kats [1962] for $\mathbf{E} \perp c$. Because the observed absorption bands in our samples were restricted to the relatively narrow interval 320-360 $\mathrm{mm}^{-1}$, it was not necessary to make a correction for the wave number dependence [Paterson, 1982] of molar absorptivity.

Owing to the relatively transparent surfaces and crack-free nature of the hydrothermally annealed samples, impregnating media were not needed for IR absorption measurements. Scattering losses from high densities of microcracks in deformed specimens, however, prevented their direct measurement. Rather than using impregnating media for their measurement, IR spectra of these samples were assumed to be the same as those of samples annealed hydrostatically under the same conditions of $T, P_{\mathrm{H}_{2} \mathrm{O}}$, and annealing time $t$. Although nominally dry, we suspect that impregnating media such as $\mathrm{KBr}$ and $\mathrm{C}_{4} \mathrm{Cl}_{6}$ may contain trace concentrations of water unless great care is taken to dry them and remove surface layers of water adsorbed on microcracks within samples prior to their use. 


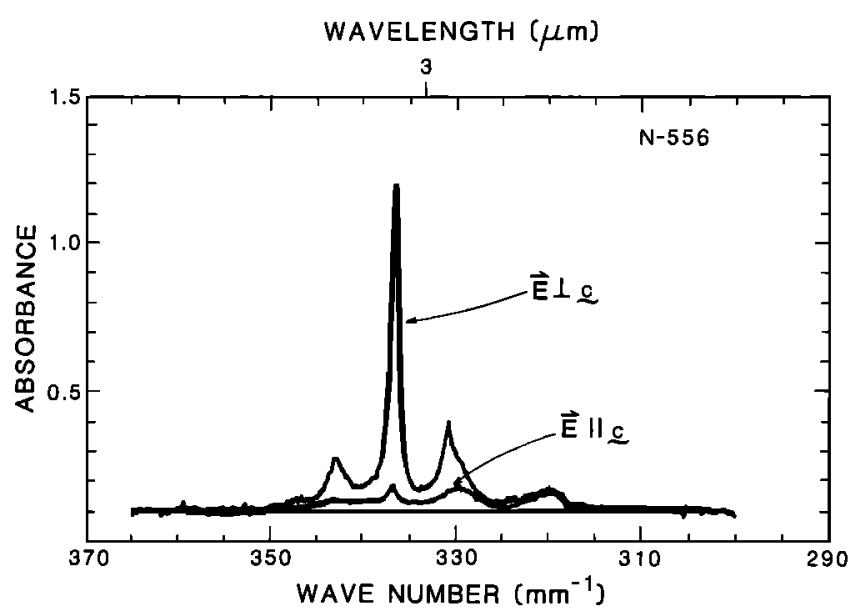

Fig. 6. Polarized IR absorption spectra of hydrothermally annealed Brazilian quartz crystal N-556 (annealed at $T=800^{\circ} \mathrm{C}$, $P_{\mathrm{H}_{2} \mathrm{O}}=890 \mathrm{MPa}, t=1.77 \times 10^{5}$ s). Absorption bands at $330.5,337.1$, and $343.5 \mathrm{~mm}^{-1}$ are strongly dichoric with maximum peak heights measured with $\mathbf{E} \perp c$ (spectra measured at $T=77 \mathrm{~K}$, polarized IR beam perpendicular to $c, L=4.38 \mathrm{~mm}$ ). The three major absorptions have been identified by Kats [1962] as being due to $\mathrm{OH}$ groups associated with $\mathrm{Al}$ impurities.

\section{RESULTS}

IR measurements at room temperature of the quartz starting materials and hydrothermally annealed crystals $\left(T=700^{\circ}-900^{\circ} \mathrm{C}, P_{\mathrm{H}_{2} \mathrm{O}}=400-1550 \mathrm{MPa}\right)$ were used to determine the changes in peak heights and integrated areas of absorption bands in the $340 \mathrm{~mm}^{-1}$ region and are summarized in Table 2. Absorption band assignments, listed in Table 3, were made by comparison of IR measurements at liquid $\mathrm{N}_{2}$ temperature $(T=77 \mathrm{~K})$ with absorption bands identified by Kats [1962]. Table 4 contains chemical analyses of annealed Brazilian quartz crystals, and Table 5 lists the diffusion coefficients for hydrogen in quartz determined from the rates of uptake and of hydrogen-deuterium exchange. The results of constant strain rate experiments performed on dry and hydrothermally annealed quartz crystals shortened in the $\mathrm{O}^{+}$ orientation are listed in Table 6.

\section{Hydrogen Uptake at Elevated $P_{\mathrm{H}_{2} \mathrm{O}}$}

IR absorption spectra of quartz single crystals annealed at elevated water pressures exhibit growth of absorption bands in the range of $320-360 \mathrm{~mm}^{-1}$ (Figure 4), most of which are present in spectra of the starting materials and which are due to fundamental O-H stretching modes [Kats, 1962] (see Aines and Rossman [1984] for review). Measured at liquid $\mathrm{N}_{2}$ temperature (Figure 5), these absorption bands are extremely sharp (with measured band widths limited by the working resolution of $0.2 \mathrm{~mm}^{-1}$ ) and are effectively separated, revealing an apparently flat background. A broad absorption band resembling those of synthetic quartz and amethyst crystals [Kekulawala et al., 1981; Aines and Rossman, 1984] was not observed in any of our samples. In addition to their sharp nature, the principal absorption bands near $340 \mathrm{~mm}^{-1}$ are strongly dichroic, as shown by spectra measured using a polarized incident IR beam perpendicular to $c$ (Figure 6) with maximum peak heights measured for $\mathbf{E} \perp c$ and minimum absorbances for $\mathbf{E} \| c$,

Difference spectra of samples annealed in isotopically normal water and in water labeled with $99.8 \%$ deuterium (atoms $\mathrm{D} / \mathrm{H}$ ) and $98.4 \%$ oxygen 18 (atoms ${ }^{18} \mathrm{O} /{ }^{16} \mathrm{O}$ ) were measured to test our assumption that the principal absorptions which grow at elevated $P_{\mathrm{H}_{2} \mathrm{O}}$ are due to $\mathrm{O}-\mathrm{H}$ stretching modes. Difference spectra were determined by subtracting the starting material spectrum from the spectra of annealed crystals (Figure 5) after normalizing with respect to sample thick. ness according to Beer's law. These difference spectra, therefore, reveal the growth of those absorption bands corresponding to stable defects by positive deflections and the decrease of absorptions associated with defects which are unstable at the experimental conditions by negative deflections. Spectral shifts in the difference spectra of samples annealed in $\mathrm{H}_{2} \mathrm{O}, \mathrm{D}_{2} \mathrm{O}$, and $\mathrm{H}_{2}{ }^{18} \mathrm{O}$ have been compared with those expected from the reduced masses $\mu_{r}$ of idealized $\mathrm{O}-\mathrm{H}, \mathrm{O}-\mathrm{D}$, and ${ }^{18} \mathrm{O}-\mathrm{H}$ harmonic oscillators (where $\mu_{r}=m_{1} m_{2} /\left(m_{1}+m_{2}\right)$ ) assuming that their
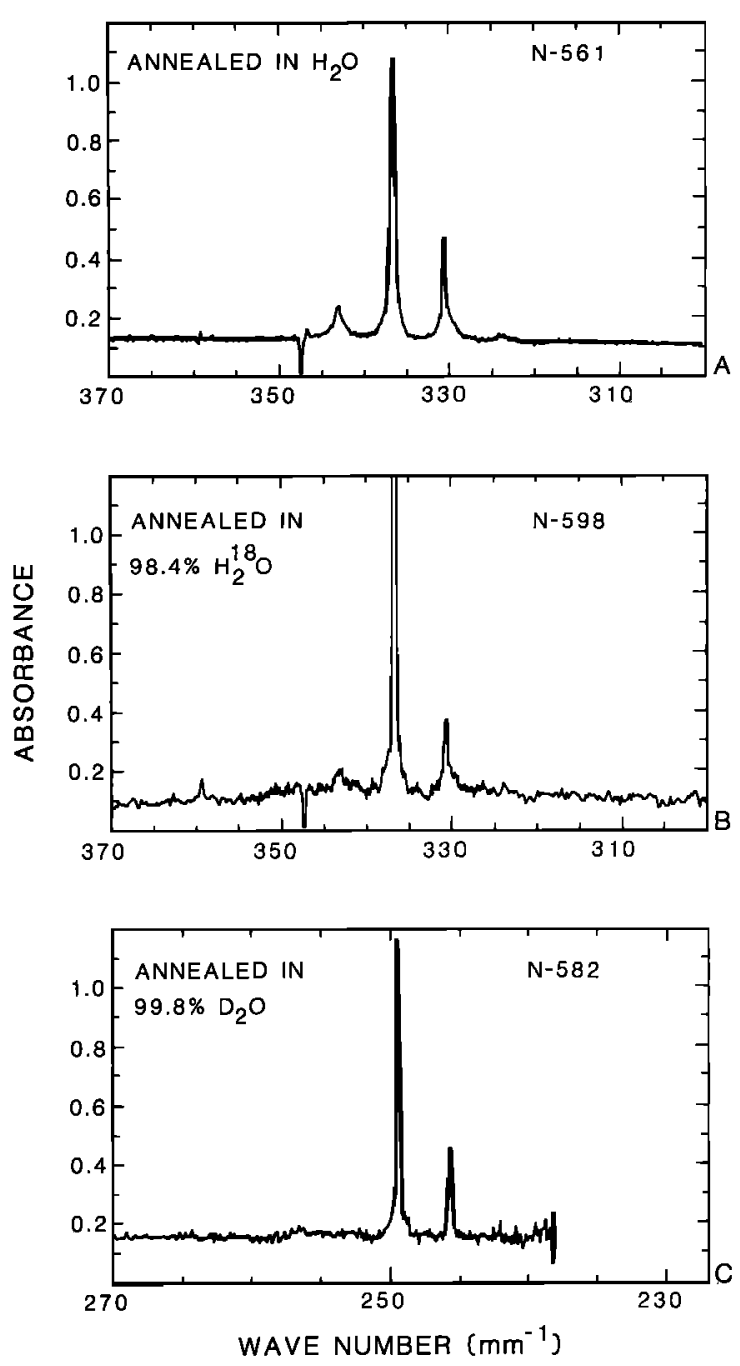

Fig. 7. IR difference spectra for Brazilian quartz samples $(a)$ annealed in isotopically normal $\mathrm{H}_{2} \mathrm{O}\left(\mathrm{N}-561, T=800^{\circ} \mathrm{C}, P_{\mathrm{H}_{2} \mathrm{O}}=890\right.$ $\mathrm{MPa}, t=1.74 \times 10^{5} \mathrm{~s}$ using $\mathrm{H}_{2} \mathrm{O}+\mathrm{Mg}(\mathrm{OH})_{2}+\mathrm{MgO}$ fluid source), (b) annealed in 98.4 atom $\%{ }^{18} \mathrm{O}$-enriched $\mathrm{H}_{2}{ }^{18} \mathrm{O}\left(\mathrm{N}-598, T=800^{\circ} \mathrm{C}\right.$, $\left.P_{\mathrm{H}_{2} \mathrm{O}}=1100 \mathrm{MPa}, t=3.8 \times 10^{5} \mathrm{~s}\right)$, and $(c)$ annealed in 99.8 atom \% deuterium-enriched $\mathrm{D}_{2} \mathrm{O}\left(\mathrm{N}-582, T=800^{\circ} \mathrm{C}, P_{\mathrm{H}_{2} \mathrm{O}}=1070 \mathrm{MPa}\right.$, $T=1.73 \times 10^{5}$ s). Spectral shifts of the principal stable absorption bands are observed corresponding to the reduced masses of the O-H and O-D oscillators (N-561 and N-582). The shift expected for ${ }^{16} \mathrm{O}-\mathrm{H}$ and ${ }^{18} \mathrm{O}-\mathrm{H}$ stretching modes $(\mathrm{N}-561$ and $\mathrm{N}-598)$, however, is not observed (all spectra measured at $T=77 \mathrm{~K}$, unpolarized IR beam parallel to $c, L=3.29 \mathrm{~mm}$ for all three samples). 


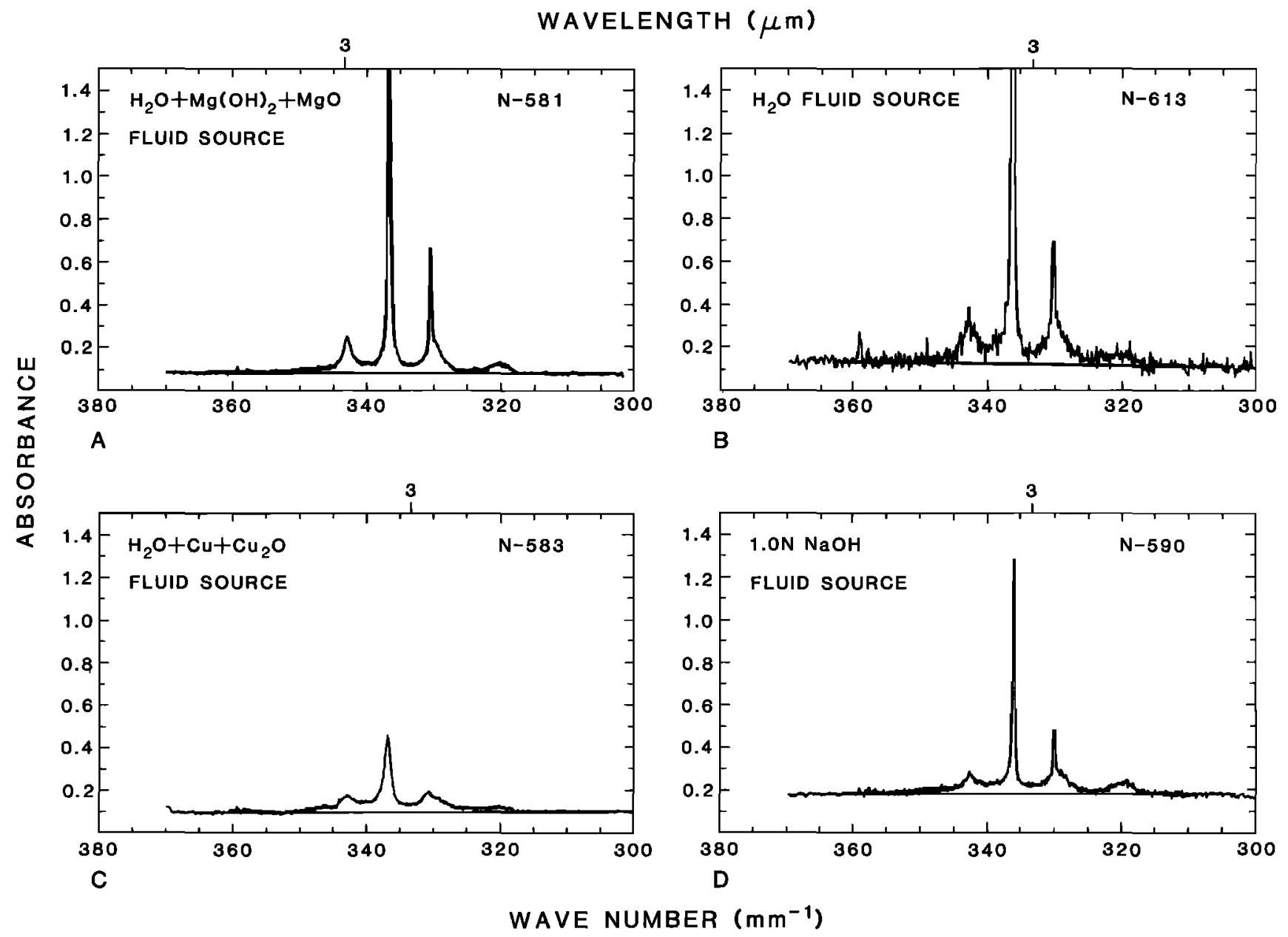

Fig. 8. Liquid $\mathrm{N}_{2}$ temperature $(77 \mathrm{~K}$ ) IR absorption spectra of Brazilian quartz crystals annealed in various fluids, including (a) $\mathrm{H}_{2} \mathrm{O}+\mathrm{Mg}(\mathrm{OH})_{2}+\mathrm{MgO}\left(\mathrm{N}-581, L=3.31 \mathrm{~mm}, T=800^{\circ} \mathrm{C}, P_{\mathrm{H}_{2} \mathrm{O}}=890 \mathrm{MPa}, t=6.04 \times 10^{5} \mathrm{~s}\right),(b) \mathrm{H}_{2} \mathrm{O}$ $\left(\mathrm{N}-613, L=2.75 \mathrm{~mm}, T=900^{\circ} \mathrm{C}, P_{\mathrm{H}_{2} \mathrm{O}}=1550 \mathrm{MPa}, t=3.75 \times 10^{6} \mathrm{~s}\right),(c) \mathrm{H}_{2} \mathrm{O}+\mathrm{Cu}+\mathrm{Cu}_{2} \mathrm{O}(\mathrm{N}-583, L=1.78 \mathrm{~mm}$, $\left.T=800^{\circ} \mathrm{C}, P_{\mathrm{H}, \mathrm{O}}=1550 \mathrm{MPa}, P_{\mathrm{O}_{2}}=10^{-10} \mathrm{MPa}, t=1.73 \times 10^{5} \mathrm{~s}\right)$, and $(d) 1.0 \mathrm{~N} \mathrm{NaOH}$ solution (N-590, $L=3.34 \mathrm{~mm}$, $T=800^{\circ} \mathrm{C}, P_{\mathrm{H}_{2} \mathrm{O}}=1150 \mathrm{MPa}, t=1.73 \times 10^{5} \mathrm{~s}$ ). The speciation of hydrogen defects appears to be unaffected by fluid chemistry, and ultimate $\mathbf{H}$ concentrations are comparable when normalized for sample thickness (unpolarized IR beam parallel to c)

force constants are the same [Colthup et al., 1964]. In accordance with the reduced masses of O-H and O-D, the difference spectra of samples annealed in isotopically normal and deuterated water (Figure 7) show a shift of the stable absorptions at $v=336.4$ and $330.3 \mathrm{~mm}^{-1}$ (for samples annealed in $\mathrm{H}_{2} \mathrm{O}$ ) to $v=249.4$ and $245.6 \mathrm{~mm}^{-1}$ (for samples annealed in $\mathrm{D}_{2} \mathrm{O}$ ). However, the spectral shift of $\sim 1.0 \mathrm{~mm}^{-1}$ expected from the reduced masses of ${ }^{16} \mathrm{O}-\mathrm{H}$ and ${ }^{18} \mathrm{O}-\mathrm{H}$ stretching modes has not been observed; the stable IR bands of samples annealed in $\mathrm{H}_{2}{ }^{16} \mathrm{O}$ and $\mathrm{H}_{2}{ }^{18} \mathrm{O}$ were observed to occur at precisely the same wave numbers within the precision of the measurements $\left( \pm 0.1 \mathrm{~mm}^{-1}\right)$. These observations therefore support our initial assertion that the stable absorption bands result from $\mathrm{O}-\mathrm{H}$ stretching. Furthermore, hydrogen is introduced from the fluid, but the bulk of oxygen in the quartz samples could not have exchanged with oxygen of the fluid. To the limit of our observations, then, hydrogen does not diffuse in the form of $\mathrm{OH}$ or $\mathrm{H}_{2} \mathrm{O}$.

\section{Absence of Intracrystalline Water}

While we observe the growth of absorption bands due to $\mathrm{O}-\mathrm{H}$ stretching modes in natural quartz crystals annealed at high water pressures $\left(P_{\mathrm{H}_{2} \mathrm{O}}=400-1550 \mathrm{MPa}\right)$, several lines of evidence suggest that the defect related to the phenomenon of hydrolytic weakening has not entered the quartz structure. The most important of these is the lack of any detectable broad absorption band resembling those of synthetic quartz and amethyst crystals which are reproducibly weak [Paterson and Kekulawala, 1979; Kekulawala et al., 1981].

Most experimental studies of hydrolytic weakening since those of Griggs and Blacic [1964, 1965] have been done on synthetic quartz crystals [Baëta and Ashbee, 1967, 1969a, b; Hobbs et al., 1972; Balderman, 1974; Morrison-Smith et al., 1976; Ball and Glover, 1979; Kirby and McCormick, 1979; Linker and Kirby, 1981; Trepied and Doukhan, 1982; Linker et al., 1984] which contain relatively large concentrations of water as growth defects. It is for these quartz crystals that variations in flow strength have been correlated in a systematic way with the integrated absorbance of a broad, isotropic band due to $\mathrm{O}-\mathrm{H}$ stretching, centered at $340 \mathrm{~mm}^{-1}$ and spanning wave numbers of $260-360 \mathrm{~mm}^{-1}$. The widespread comparisons, therefore, of the mechanical behaviors of synthetic quartz and of hydrothermally treated natural quartz have implicitly assumed that the same $\mathrm{OH}$ defect, responsible for the broad absorption band, is taken up by natural quartz crystals by diffusive transport. Although at high temperatures this ab- 


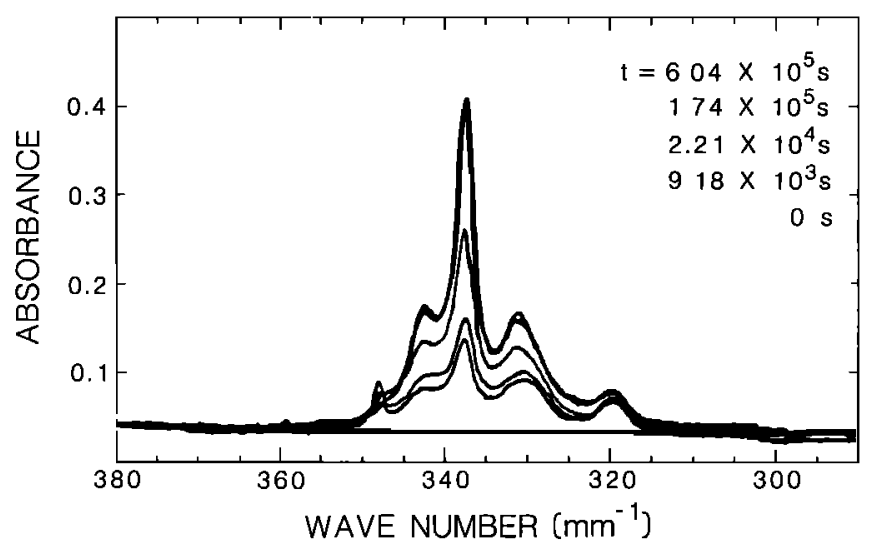

A

UPTAKE OF H ALONG C AXIS

$$
\begin{aligned}
& \mathrm{T}=800^{\circ} \mathrm{C} \\
& \mathrm{P}_{\mathrm{H}_{2} \mathrm{O}}=890 \mathrm{MPa}
\end{aligned}
$$
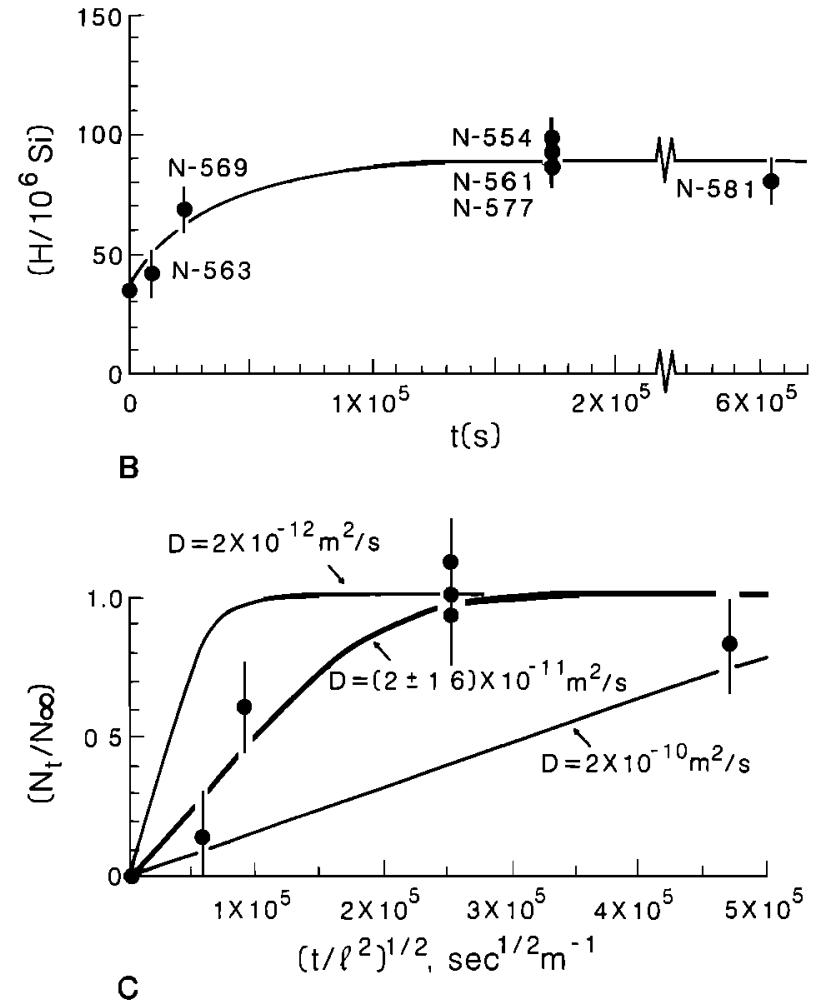

Fig. 9. Hydrogen uptake as a function of time. (a) Room temperature IR absorption spectra of Brazilian quartz crystals (unpolarized IR beam parallel to $c$ ) annealed at $T=800^{\circ} \mathrm{C}, P_{\mathrm{H}_{2} \mathrm{O}}=890 \mathrm{MPa}$ for times of $t=0 \mathrm{~s}$ (A-1 starting material, $L=3.26 \mathrm{~mm}), t=9.18 \times 10^{3} \mathrm{~s}(\mathrm{~N}-563, L=3.28 \mathrm{~mm}), t=2.21 \times 10^{4} \mathrm{~s}(\mathrm{~N}-569, L=3.28 \mathrm{~mm}), t=1.74 \times 10^{3} \mathrm{~s}$ $(\mathrm{N}-561, L=3.29 \mathrm{~mm})$, and $t=6.04 \times 10^{5} \mathrm{~s}(\mathrm{~N}-581, L=3.31 \mathrm{~mm})$. (b) Bulk hydrogen contents determined from integral absorbances versus time. (c) Net transport of hydrogen $N_{\text {, }}$ (normalized with respect to its ultimate uptake $N_{\text {a }}$ at $t=\infty$ ) versus $\left(t / l^{2}\right)^{1 / 2}$, where $l$ is the half thickness of the sample $(L / 2)$. Plotting solutions for one-dimensional diffusion, the diffusion coefficient $D$ for hydrogen uptake parallel to $c$ is constrained by the data to $(2 \pm 1.6) \times 10^{-11} \mathrm{~m}^{2} / \mathrm{s}$.

sorption band appears to be unstable at ambient pressure [Bastin and Mitchell, 1961; Dodd and Fraser, 1965, 1967; Bambauer et al., 1969], Kekulawala et al. [1981] reported a limited solubility of this defect at $P=300 \mathrm{MPa}$ at $T=900^{\circ} \mathrm{C}$ and suggested that the broad band may be further stabilized by higher pressures.

The broad nature of the absorption band in synthetic quartz and the lack of any apparent crystallographic relationship with the structure of quartz led initially to its characterization as some form of structurally incorporated, gel-type hydroxyl [Kirby, 1975; Kekulawala et al., 1981]. However, Aines et al. [1984] have now shown that the broad absorption band is due to molecular water. This broadband molecular water is distinguished from $\mathrm{H}_{2} \mathrm{O}$ fluid inclusions by the lack of a shift in its infrared absorption (exhibited by the water to ice transition) from its location measured at room temperature and at liquid $\mathrm{N}_{2}$ and $\mathrm{He}_{2}$ temperatures.

Contrary to our initial expectations, and in sharp contrast to recent results of Ord and Hobbs [1983] and Mackwell and Paterson [1985], natural quartz crystals annealed at elevated water pressures and temperatures (those conditions purported to promote hydrolytic weakening) do not contain molecular water (the defect known to weaken synthetic quartz) even after annealing times of up to 6 weeks at $P_{\mathrm{H}_{2} \mathrm{O}}=1550 \mathrm{MPa}$ and $T=900^{\circ} \mathrm{C}$ (Figure $8 b$ ). IR spectra of our hydrothermally treated quartz crystals exhibit sharp dichroic absorption bands, distinct from the broad isotropic absorption of synthetic quartz, with peak locations identical to those assigned to $\mathbf{H}_{\mathbf{x}}$ 'by Kats [1962]. The lack of a spectral shift for the sample $(\mathrm{N}-598)$ annealed in ${ }^{18} \mathrm{O}$-labeled water, furthermore, rules out any significant exchange of oxygen between the fluid and the bulk of the quartz specimen. The defect responsible for the broad band [Aines et al., 1984] is molecular water $\left(\mathrm{H}_{2} \mathrm{O}\right)_{i}{ }^{x}$, and its diffusive transport, neglecting any charge transfer reactions, would appear to require oxygen transport.

\section{Solubility and Diffusion of Hydrogen}

Although our hydrothermal annealing experiments were carried out at high water pressures (up to $1550 \mathrm{MPa}$ ), all of the sharp absorption bands reported here (Table 3) have been observed previously by Kats [1962] and Kats et al. [1962] in natural quartz crystals annealed at water pressures of only 2.5 MPa. Kats [1962] was able to identify those $\mathrm{H}$ defects which are associated with other impurities, on the basis of chemical analyses and electrolytic exchanges. The principal absorptions which are stable at high $P_{\mathrm{H}_{2} \mathrm{O}}$ are due to $\mathrm{O}-\mathrm{H}$ stretching in the vicinity of Al impurities, whereas several of the absorption bands which are unstable at high water pressures are due to $\mathrm{O}-\mathrm{H}$ vibrations near $\mathrm{Li}$ impurities. Correspondingly, the equilibrium solubility of hydrogen in annealed quartz samples appears to be related directly to the initial $\mathrm{Al}$ content.

Equilibrium hydrogen concentrations were determined from the integral absorptions of samples annealed at long times (e.g., $t \geq 2$ days at $T=800^{\circ} \mathrm{C}, t \geq 10$ days at $T=700^{\circ} \mathrm{C}$ ). Although the time required for equilibration depends upon the experimental conditions, the speciation of hydrogen defects and their ultimate concentrations (Figure 8) appear to be independent of $T, P_{\mathrm{H}_{2} \mathrm{O}}, P_{\mathrm{O}_{2}}$, and fluid chemistry over the full range of experimental conditions $\left(700^{\circ} \leq T \leq 900^{\circ} \mathrm{C}, P_{\mathrm{H}_{2} \mathrm{O}}\right.$ up 


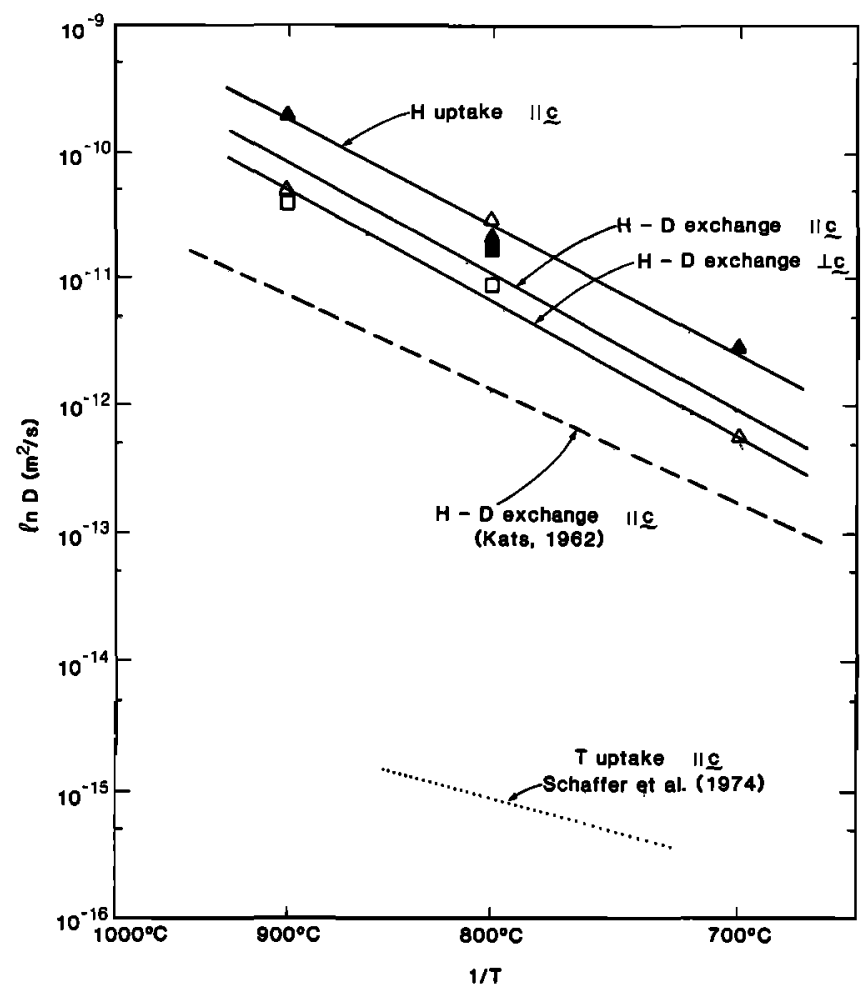

Fig. 10. Arrhenius plot ( $\ln D$ versus $1 / T)$ of $\mathbf{H}$ diffusion at elevated $P_{\mathrm{H}_{2} \mathrm{O}}$ (in the range of 890-1540 MPa), based upon hydrogen uptake ( $\| c$ solid triangles, $\perp c$ solid squares) and upon hydrogen-deuterium exchange ( $\| c$ open triangles, $\perp c$ open squares). The results of $K a t s$ [1962] for hydrogen-deuterium exchange $\| c$ at $P_{\mathrm{H}_{2} \mathrm{O}}=2.5 \mathrm{MPa}$ are shown as a dashed line; those of Shaffer et al. [1974] for tritium uptake $\| c$ at $P_{\mathrm{H}_{2} \mathrm{O}}=0.06 \mathrm{MPa}$ are shown as a dotted line.

to $1550 \mathrm{MPa}, P_{\mathrm{O}_{2}}$ up to $10^{-10} \mathrm{MPa}$, in fluids as diverse as distilled $\mathrm{H}_{2} \mathrm{O}$ and $1.0 \mathrm{~N} \mathrm{NaOH}$ ). The ultimate $\mathrm{H}$ concentration appears to depend upon the initial Al content; $\mathrm{H}$ concentrations of samples taken from crystal A-1 (83 \pm 10

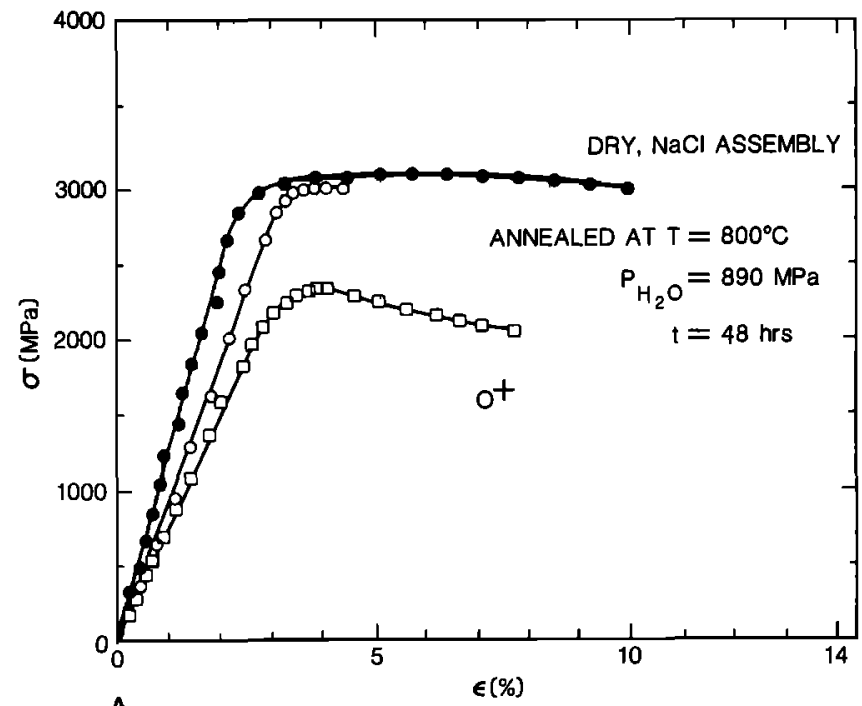

ppm) are in close agreement with its initial $\mathrm{Al}$ content of $91 \pm 1$ ppm (though the correspondence of $\mathbf{H}$ content $(181 \pm 18 \mathrm{ppm})$ with $\mathrm{Al}(300 \mathrm{ppm})$ is less clear for crystal Q-37). We expect that, at equilibrium, hydrogen interstitials $\mathrm{H}_{i}{ }^{\prime}$ are paired with aluminum substitutions for silicon $\mathrm{Al}_{\mathrm{SI}}{ }^{\prime}$ by the local charge neutrality condition $\left[\mathrm{H}_{i}{ }^{\circ}\right]=\left[\mathrm{Al}_{\mathrm{Si}^{\prime}}{ }^{\prime}\right.$. Though stable $\mathrm{Al}_{\mathrm{Si}}{ }^{\prime}$ concentrations may, in turn, depend upon such variables as $T, P_{\mathrm{H}_{2} \mathrm{O}}$, and $P_{\mathrm{O}_{2}}$, chemical analyses of annealed Brazilian quartz crystals (Table 4) indicate that the Al contents of our specimens have not changed over the experimental times. In fact, the very low mobilities of $\mathrm{Al}$ and $\mathrm{Si}$ in quartz (B. J. Giletti and R. A. Yund, personal communication, 1985) suggest that equilibrium with respect to Al content cannot be attained in experimental times. Thus the state of equilibrium defined here for $\mathrm{H}_{i}$ assumes a particular, unchanging $\mathrm{Al}_{\mathrm{si}}$ ' concentration.

The attainment of equilibrium hydrogen concentrations was tested for, and the diffusional kinetics of hydrogen interstitials studied, by measuring the uptake of $\mathrm{H}$ as a function of time. Room temperature IR spectra measured with the beam $\| c$ for quartz crystals annealed at $T=800^{\circ} \mathrm{C}, P_{\mathrm{H}_{2} \mathrm{O}}=890 \mathrm{MPa}$, and times ranging from $\sim 2$ hours $\left(9.18 \times 10^{3} \mathrm{~s}\right)$ to 1 week $(6.04$ $\left.\times 10^{3} \mathrm{~s}\right)$ show the progressive growth of the absorption bands assigned to hydrogen interstitials (Figure 9). Bulk $\mathrm{H}$ contents of these samples, determined from their integral absorbances, reveal the rapid net transport of $H$ into samples at short annealing times with uptake leveling off at times greater than $\sim 1 \times 10^{5} / \mathrm{s}$. The diffusion coefficient $D$ for hydrogen $\| c$ in quartz was determined from these bulk $H$ contents, assuming one-dimensional diffusion into a slab of half thickness $l=$ $L / 2$ ) and using the truncated series solution to Fick's second law:

$$
\frac{N_{\mathrm{t}}}{N_{\infty}}=2\left(\frac{D t}{l^{2}}\right)^{1 / 2}\left[\pi^{-1 / 2}-2 i \operatorname{erfc}\left(\frac{1}{(D t)^{1 / 2}}\right)\right]
$$

where the assumed boundary conditions are that the surface concentrations of $\mathbf{H}$ at $t \geq 0$ are equal to the ultimate solubility, and where $N_{t}$ and $N_{\infty}$ are defined as the net transport

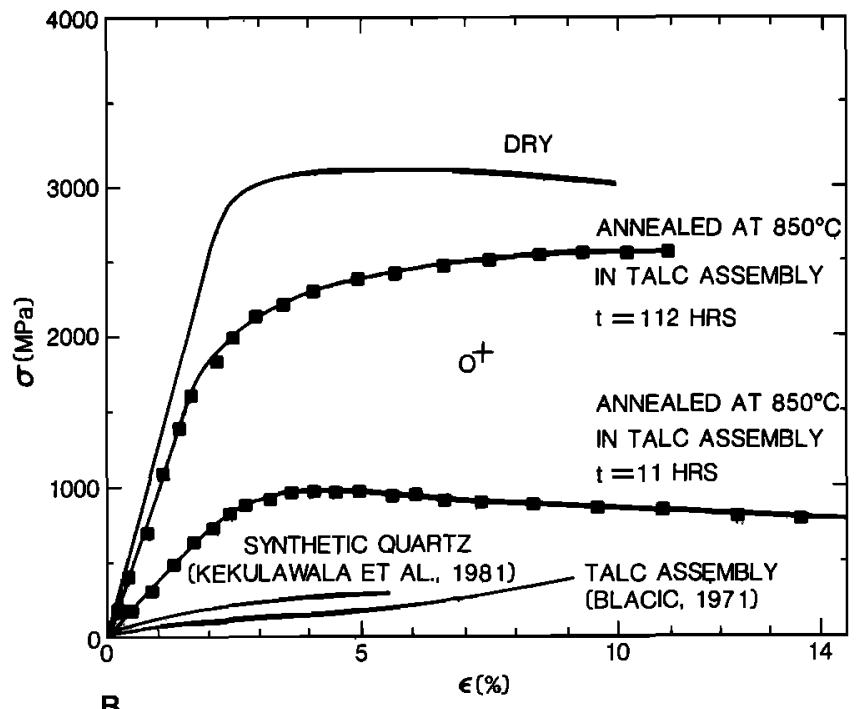

B

Fig. 11. Mechanical results for dry and hydrothermally annealed Brazilian quartz. (a) Stress $\sigma /$ strain $\varepsilon$ curves for $\mathrm{O}^{+}$ orientation single crystals, sealed in Au jackets, and deformed in $\mathrm{NaCl}$ assemblies $\left(T=800^{\circ} \mathrm{C}, P_{c}=1490-1600 \mathrm{MPa}\right.$, $\dot{\varepsilon}=1.0 \times 10^{-5} / \mathrm{s}$ ). Although the results for dry Brazilian quartz (solid circles, $\mathrm{N}-565$ ) compare favorably with those of Griggs and Blacic [1965], hydrothermally treated crystals (open squares and open circles for N-567 and N-576, respectively, both annealed at $T=800^{\circ} \mathrm{C}, P_{\mathrm{H}_{2} \mathrm{O}}=890 \mathrm{MPa}, t \simeq 1.7 \times 10^{5} \mathrm{~s}$ ) fail to show a significant reduction in yield strength. (b) Stress-strain curves of unjacketed quartz crystals $\left(\mathrm{O}^{+}\right.$orientation, $\left.T=800^{\circ} \mathrm{C}, \boldsymbol{P}_{c}=1480-1500 \mathrm{MPa}, \dot{\varepsilon}=1.0 \times 10^{-5} / \mathrm{s}\right)$ deformed in talc assemblies after annealing $\left(T=850^{\circ} \mathrm{C}, P_{c}=1480-1500 \mathrm{MPa}\right)$ for times of $\sim 11$ hours $\left(t=3.96 \times 10^{4} \mathrm{~s}\right.$, $\mathrm{N}-588)$ and $\sim 112$ hours $\left(t=4.03 \times 10^{5} \mathrm{~s}, \mathrm{~N}-587\right)$. The strength of quartz measured after $\sim 11$ hours in talc approaches that reported by Griggs and Blacic [Blacic, 1971]; however, the yield strength after $\sim 112$ hours in talc is again increased. 


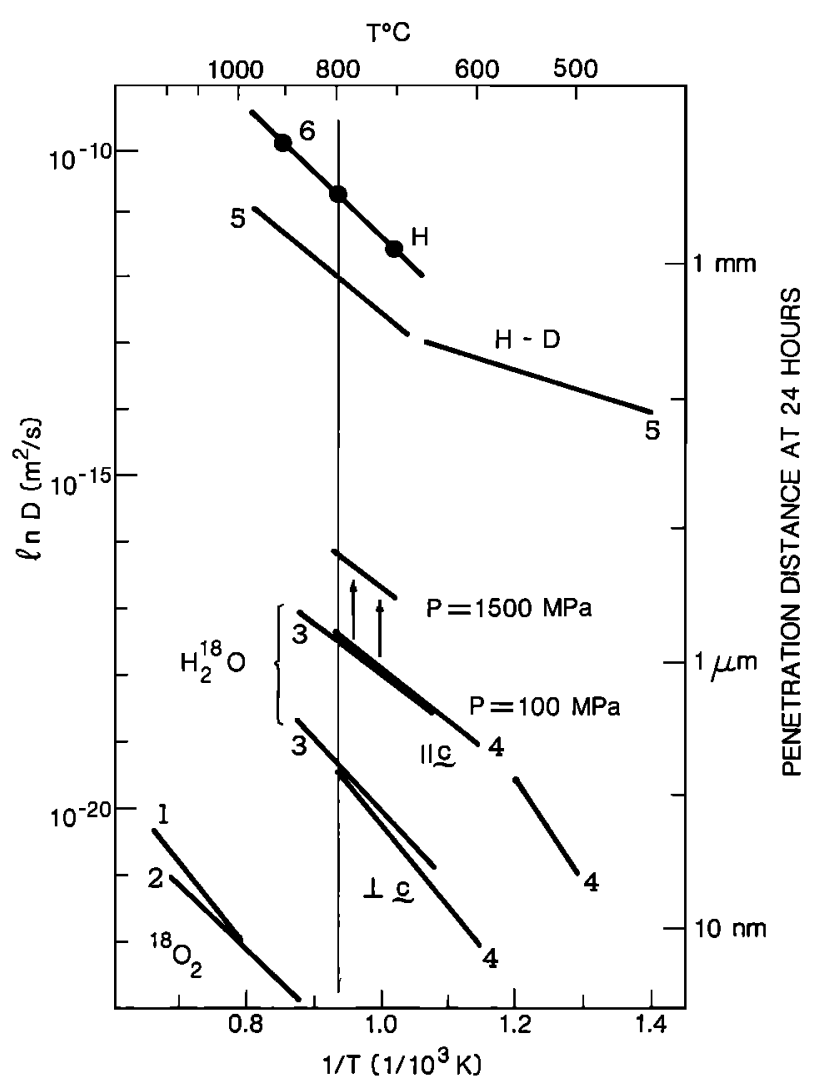

Fig. 12. Arrhenius plot (ln $D$ versus $1 / T$ ) of collected $H$ and $O$ diffusion in quartz. Despite the wide spread in the results for oxygen, the diffusion rates of hydrogen are far greater than those of oxygen under all conditions tested. Characteristic penetration distances (determined for an annealing time of 24 hours) are shown at the right (data of 1, Haul and Dümbgen [1962]; 2, Schachtner and Sockel [1977]; 3, Dennis [1984]; 4, Giletti and Yund [1984]; 5, Kats [1962]; 6 , this study).

of $\mathrm{H}$ at times $t$ and $t=\infty$, respectively [Crank, 1975]. Similarly, diffusion coefficients for $\mathbf{H}$ uptake parallel to $c$ were determined over the temperature interval $700^{\circ} \leq T \leq 900^{\circ} \mathrm{C}$, and a $D$ value perpendicular to $c$ determined at $T=800^{\circ} \mathrm{C}$ (Table 5). Because of the relatively small ultimate solubility of $\mathrm{H}$ in quartz (83 ppm for crystal A-1) and the sample-to-sample variations in integrated absorptions (yielding an uncertainty of $\pm 10 \mathrm{ppm}$ in $\mathbf{H}$ content for any particular sample), diffusion coefficients could not be determined to better than a factor of 2.

Attempts were also made to evaluate the rates of $\mathbf{H}$ uptake in quartz by serial sectioning methods. IR absorption spectra were measured before and after grinding and polishing samples (N-563, N-569) repeatedly and difference spectra calculated. These measurements yielded hydrogen concentration profiles (for 2 times $t=9.18 \times 10^{3} \mathrm{~s}$ and $t=2.21 \times 10^{4} \mathrm{~s}$, respectively) roughly consistent with the diffusion coefficient determined from the time dependence of $\mathrm{H}$ uptake at $T=800^{\circ} \mathrm{C}$. However, the scatter in integrated areas of these difference spectra (representing $\mathbf{H}$ concentrations of rather thin layers of quartz removed by grinding) led to larger uncertainties in calculated $D$ values and this approach was not pursued further.

Although the uptake of $\mathbf{H}$ in quartz is, strictly speaking, chemical diffusion (not self-diffusion), we have implicitly assumed no effects of $\mathrm{H}$ concentration upon its diffusion by using (2) to solve for hydrogen $D$ values. Over the limited range of $\mathbf{H}$ contents (from 35 to $83 \mathrm{ppm}$ ), however, we have not detected any significant deviations from this assumed solution within the precision of our measurements. In addition, the diffusion coeflicients so determined over the temperature interval of $700^{\circ}-900^{\circ} \mathrm{C}$ appear to fit an Arrhenius relation

$$
D=D_{0} \exp (-Q / R T)
$$

for uptake parallel to $c$, where $D_{0}$ is a constant and $Q$ is defined as an activation energy (Figure 10). Least squares fit to this relation, the $\mathbf{H}$ uptake data, yields

$$
\begin{aligned}
& D_{0}(\| c) \simeq 1.4 \times 10^{-1} \mathrm{~m}^{2} / \mathrm{s} \\
& Q(\| c)=200 \pm 20 \mathrm{~kJ} / \mathrm{mol}
\end{aligned}
$$

in near agreement with those of Kats [1962] for hydrogendeuterium exchange $\left(D_{0}=5 \times 10^{-4} \mathrm{~m}^{2} / \mathrm{s}, Q=176 \mathrm{~kJ} / \mathrm{mol}\right)$. They do not compare well with the results of Shaffer et al. [1974]. Although the diffusive uptake of $\mathrm{H}$ perpendicular to $c$ was only investigated at $T=800^{\circ} \mathrm{C}$, it appears to be the same.

$$
D(\perp c)=(2 \pm 1.5) \times 10^{-11} \mathrm{~m}^{2} / \mathrm{s} \quad \text { at } T=800^{\circ} \mathrm{C}
$$

within error, as that parallel to $c$. Because of the need to maintain charge neutrality, our experimentally derived terms $D, D_{0}$, and $Q$ must represent the exchange of hydrogen interstitials $\mathbf{H}_{i}$ with other charged defects originally in the starting material. Several lines of evidence, including the decrease in $\mathrm{O}-\mathrm{H}$ absorption bands associated with $\mathrm{Li}$ impurities (Table 3 ) and the drop in alkali impurity concentrations of hydrothermally annealed quartz samples (Table 4), suggest that $\mathrm{H}_{i}$ exchanges with the interstitial alkalis $\mathrm{Li}_{i}, \mathrm{Na}_{i}$, and perhaps $\mathrm{K}_{i}$.

In addition to the investigation of $\mathrm{H}$ uptake in quartz, we studied the exchange of $\mathrm{H}$ and $\mathrm{D}$ in quartz, in order to determine the mobility of hydrogen independent of concentration effects and independent of interstitial alkali diffusion. Quartz crystals were preannealed in isotopically normal water for times long enough for equilibration (with respect to $H$ ) and were then annealed in deuterium-labeled water. For these experiments, diffusion coefficients (Table 5) were determined by measuring the integrated absorbances of difference spectra (calculated from the spectra of preannealed and twiceannealed samples), both in the O-H stretch and the O-D stretch regions. The diffusion coefficients of H-D exchange compare favorably with those determined for $\mathrm{H}$ uptake with

$$
\begin{gathered}
D_{0}(\| c) \simeq 1.7 \times 10^{-1} \mathrm{~m}^{2} / \mathrm{s} \\
D_{0}(\perp c) \simeq 1.1 \times 10^{-1} \mathrm{~m}^{2} / \mathrm{s} \\
Q(\text { both } \| \text { and } \perp c)=210 \pm 87 \mathrm{~kJ} / \mathrm{mol}
\end{gathered}
$$

In contrast to the strong anisotropy of alkali diffusion in quartz [Freer, 1981], the diffusion of hydrogen is, within measurement error, isotropic.

\section{Mechanical Tests of Hydrothermally Annealed Quartz}

Because molecular water does not enter natural quartz at detectable levels under any experimental conditions tested here, the question arises how the Brazilian quartz crystals of Griggs and Blacic [1964, 1965], and of later studies [Hobbs 

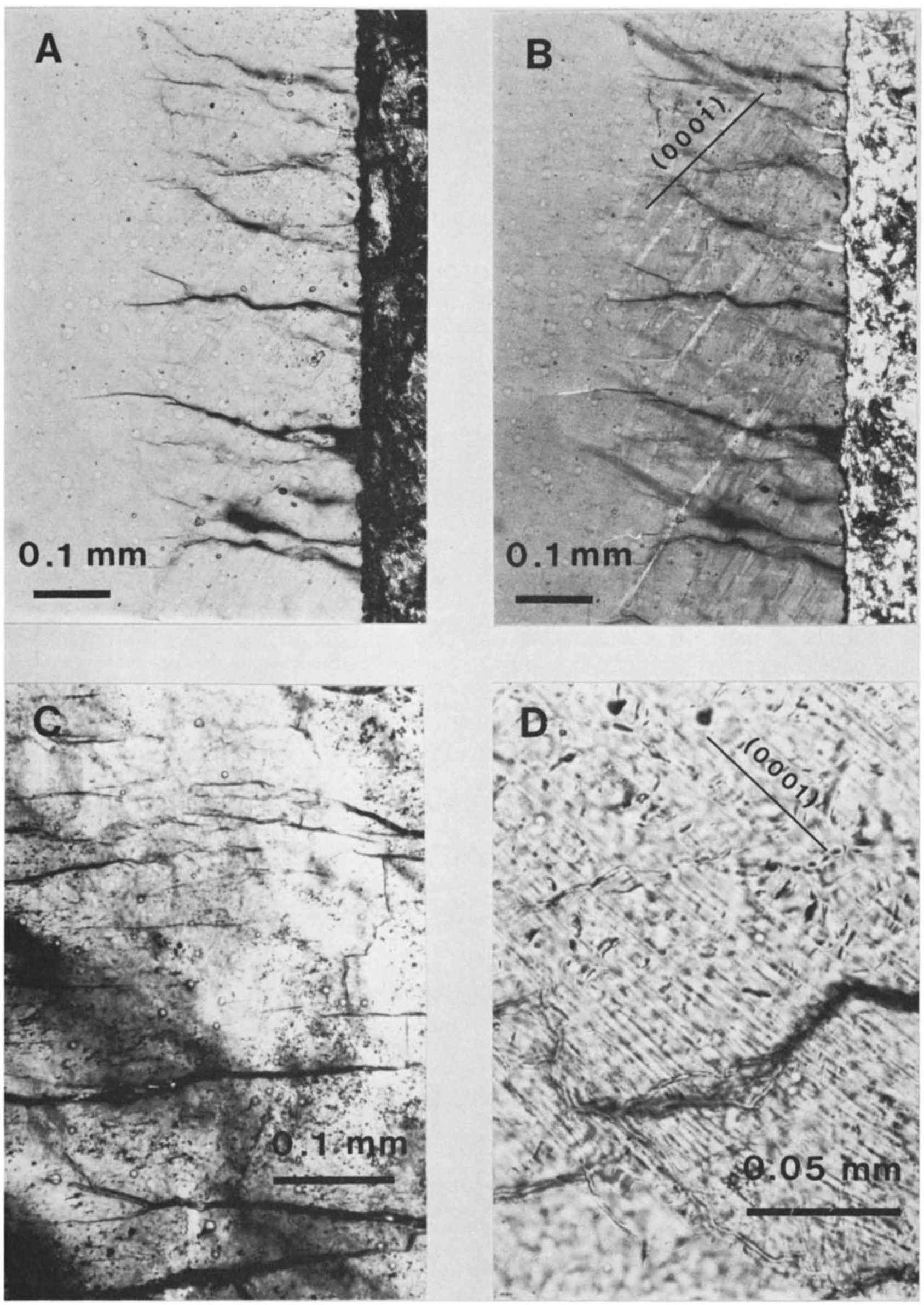
and Tullis, 1979; Ord and Hobbs, 1983, 1986; Mackwell and Paterson, 1985] performed at the same temperatures and pressures, were weakened. Kekulawala et al. [1978] were unable to weaken natural quartz crystals exhibiting sharp absorption bands (due to $\mathrm{H}_{\imath}$ ) but lacking a broad band (due to $\mathrm{H}_{2} \mathrm{O}_{i}{ }^{x}$ ). However, several theories of water weakening, since that of Frank and Griggs [Griggs, 1967, 1974], which required $\left(\mathrm{H}_{2} \mathrm{O}\right)_{1}{ }^{x}$ defects to form paired silanol defects have emphasized the influence of donors (such as $\mathrm{H}_{2}$ ) and acceptors of electrons upon the defect chemistry of quartz [Hirsch, 1981; Hobbs, 1981]. These treatments suggest the importance of elevated water pressures (perhaps greater than those used by Kekulawala et al. [1978]), as well as effects of the oxygen fugacity and extrinsic impurities such as $\mathrm{Na}_{i}$ [Jaoul, 1984] upon the deformation process.

Constant strain rate experiments were, therefore, performed on $\mathrm{O}^{+}$orientation Brazilian quartz crystals, both dry and hydrothermally annealed using the brucite-periclase buffer, at $T=800^{\circ} \mathrm{C}$ and $P_{c}=600-1600 \mathrm{MPa}$ (Table 6). The results, however, are similar to those of Kekulawala et al. [1978] at lower pressures, showing little or no influence of increased $\mathrm{H}_{i}$; concentrations upon the yield strength of quartz (Figure 11a). While our stress-strain curves for dry single crystals are in close agreement with those (Figure 1) of Griggs and Blacic [1964, 1965], we have not been able to weaken quartz crystals annealed at a water pressure of $890 \mathrm{MPa}$ (within the pressure range applied in their experiments) for times of up to 48 hours. The differing water pressures used in the studies of Griggs and Blacic [1965] and Kekulawala et al. [1981] cannot be responsible for the discrepancies between these two studies.

Because our attempts to reproduce the original GriggsBlacic experiments under controlled $P_{\mathrm{H}_{2} \mathrm{O}}$ using improved $\mathrm{NaCl}$ assemblies failed, we repeated deformation experiments on unjacketed quartz crystals using talc assemblies which, with the exception of size, were identical to those of the original study. Using these assemblies, we observe a dramatic drop in the yield strength of quartz (Figure $11 b$ ) after a relatively short annealing time ( $\sim 11$ hours), comparable with that originally reported. However, the dependence of strength upon annealing time is inconsistent with diffusional penetration [Blacic, 1981] of the single crystal by water. Yield strengths of our quartz samples are increased with increasing annealing times (from 11 to 112 hours). In addition, the drop in yield strength is observed at the same annealing times as used by Griggs and Blacic ( $~ 12$ hours), despite the larger $(\times 2)$ size of our samples. While the increase in strength with increasing annealing time may be due to $\mathrm{H}_{2} \mathrm{O}$ loss from the sample assembly (and thus a reduction in $P_{\mathbf{H}_{2} \mathrm{O}}$ ), the low strength of our sample measured after only $\sim 11$ hours annealing is inconsistent with the expected fourfold increase in time (over that used by Griggs and Blacic) required for the diffusional net transport of water into our larger samples.

Fig. 13. (opposite) Photomicrographs of Brazilian quartz crystals annealed and deformed in talc assemblies. (a) Fine, evenly spaced microcracks (apparently caused by coring) in annealed single crystal $\left(\mathrm{N}-589, T=850^{\circ} \mathrm{C}, P_{c}=1520 \mathrm{MPa}, t=4.39 \times 10^{5} \mathrm{~s}\right.$ ) as seen in plane light. (b) Basal deformation lamellae, associated with these microcracks (same section of $\mathrm{N}-589$ ) as seen between crossed nicols. (c) Microcracks and flud inclusions, in addition to undulatory extinction, in hydrothermally annealed $\left(T=850^{\circ} \mathrm{C}, P_{c}=1480 \mathrm{MPa}, t=\right.$ $3.96 \times 10^{4}$ s) and deformed $\left(T=800^{\circ} \mathrm{C}, P_{\mathrm{c}}=1480 \mathrm{MPa}, \dot{\varepsilon}=1.0\right.$ $\times 10^{-5} / \mathrm{s}$ ) quartz crystal N-588 (crossed nicols). Compression axis is vertical. (d) Basal deformation lamellae within central region of same sample ( $\mathrm{N}-588$, crossed nicols).

\section{DisCUSSION}

The spectral and mechanical results of this study for natural quartz crystals, hydrothermally annealed and deformed at elevated water pressures (up to $1550 \mathrm{MPa}$ ), parallel those of more comprehensive studies carried out at lower water pressures [Kats, 1962; Kats et al., 1962; Paterson and Kekulawala, 1979; Kekulawala et al., 1981]. They are at variance with other high-pressure studies of hydrolytic weakening [Griggs and Blacic, 1964, 1965; Hobbs and Tullis, 1979; Ord and Hobbs, 1983, 1986; Mackwell and Paterson, 1985] and the large effects of pressure upon the mobility and solubility of broadband water suggested by these studies. Nevertheless, the suggested incorporation of the defect responsible for broadband absorption into crystals $>3 \mathrm{~mm}$ in dimension by solidstate diffusion (within experimental times) is difficult to reconcile with its assignment to $\left(\mathrm{H}_{2} \mathrm{O}\right)_{i}{ }^{x}$ and the available oxygen diffusion data.

Hydrogen is taken up by quartz at $P_{\mathrm{H}_{2} \mathrm{O}}=1500 \mathrm{MPa}$, into the same interstitial sites, and at the same rates as at low water pressures. Its solubility, independent of $T, P_{\mathrm{H}_{2} \mathrm{O}}$, and $P_{\mathrm{O}_{2}}$, depends simply upon the $\mathrm{Al}$ content of the crystal and its uptake, as originally suggested by Kats [1962], appears to proceed by exchange with alkali interstitials initially in the starting material.

In accord with the results of Kekulawala et al. [1981], hydrogen interstitials do not weaken quartz. Contrary to the results of Ord and Hobbs [1983, 1986] and Mackwell and Paterson [1985], however, the defect $\left(\mathrm{H}_{2} \mathrm{O}\right)_{i}{ }^{x}$ assigned to the broad absorption band of synthetic quartz [Aines et al., 1984] and responsible for its anomalous weakness is not taken up by natural quartz crystals annealed at high $P_{\mathrm{H}_{2} \mathrm{O}}$ to any significant concentration. As a result, mechanical tests of hydrothermally annealed quartz crystals fail to show water weakening.

While the rates of hydrogen diffusion are clearly rapid enough for equilibration within experimental times, the uptake of molecular water by quartz appears to be limited by the much lower diffusion rates of oxygen (Figure 12). The lack of any significant oxygen exchange in our experiments at high $\boldsymbol{P}_{\mathrm{H}_{2} \mathrm{O}}$ (N-598 in Figure 7) is consistent with the collected results for oxygen diffusion measured over water pressures of $\sim 0-350$ MPa [Haul and Dümbgen, 1962; Choudhury et al., 1965; Giletti et al., 1976; Schachtner and Sockel, 1977; Freer and Dennis, 1982; Dennis, 1984; Giletti and Yund, 1984]. Oxygen $D$ values, measured at $T=800^{\circ} \mathrm{C}$ and $P_{\mathrm{H}_{2} \mathrm{O}}=100 \mathrm{MPa}$ [Dennis, 1984; Giletti and Yund, 1984] yield characteristic diffusion penetration distances for oxygen into quartz of only $\sim 1 \mu \mathrm{m}$ for an annealing time of 24 hours. Furthermore, while there is some controversy over the effect of water pressure upon oxygen diffusion [Dennis, 1984], the nearly linear dependence of oxygen diffusion upon $P_{\mathrm{H}_{2} \mathrm{O}}$, reported by Giletti and $Y$ und [1984], leads to penetration distances no greater than $10 \mu \mathrm{m}$ at a water pressure of $1500 \mathrm{MPa}$.

By what mechanism, then, could molecular water enter quartz crystals to a depth of $\sim 3 \mathrm{~mm}$, and what uncontrolled variable is responsible for the discrepancies in high pressure experiments? Ord and Hobbs [1983, 1986] have argued that high oxygen fugacities are required for its incorporation, and yet our results at an oxygen fugacity of $10^{-10} \mathrm{MPa}(\mathrm{N}-583$ in Figure 8) using the $\mathrm{H}_{2} \mathrm{O}+\mathrm{Cu}+\mathrm{Cu}_{2} \mathrm{O}$ fluid source are inconsistent with this suggestion. Furthermore, while the $f_{\mathrm{O}_{2}}$ is not explicitly controlled in experiments using the $\mathrm{H}_{2} \mathrm{O}$ and $\mathrm{H}_{2} \mathrm{O}+\mathrm{Mg}(\mathrm{OH})_{2}+\mathrm{MgO}$ fluid sources, we expect oxygen fugacities to fall in the range of $10^{-17} \mathrm{MPa}$ from the dissociation constant of water assuming no hydrogen loss (any $\mathrm{H}_{2}$ loss 


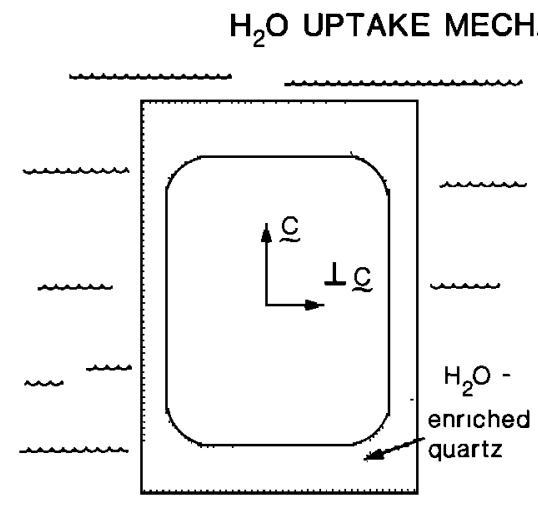

A BULK CRYSTAL DIFFUSION

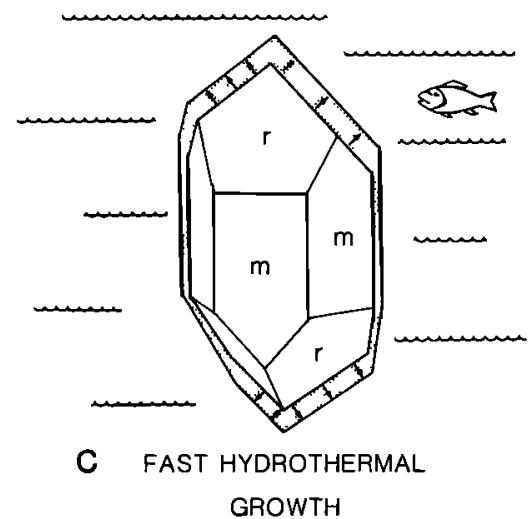

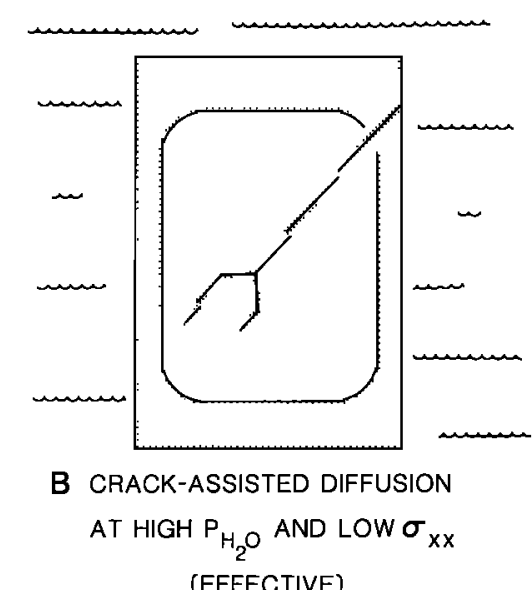

(EFFECTIVE)

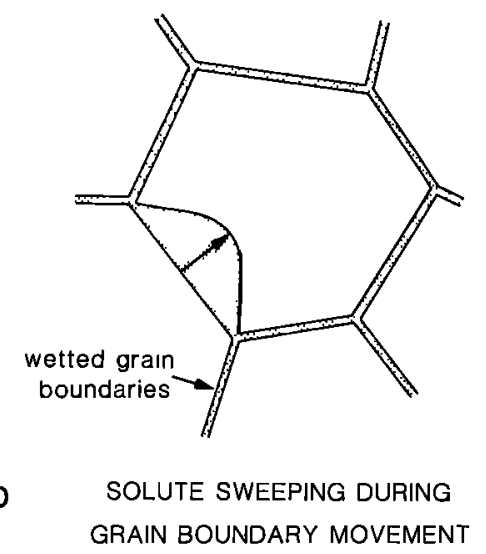

Fig. 14. Mechanisms of $\mathrm{H}_{2} \mathrm{O}$ uptake in quartz. (a) Bulk crystal diffusion. Given enough time, $\mathrm{H}_{2} \mathrm{O}$ may be taken up (shown as stippled region) by volume diffusion to equilibrium concentrations. (b) Crack-assisted diffusion. The uptake of water may be more rapid if water penetrates the sample along microcracks followed by volume diffusion. (c) Hydrothermal growth. Water may be incorporated during crystal growth, either at equilibrium concentrations during slow growth or at larger, nonequilibrium concentrations at fast growth rates. (d) If grain boundaries are wetted, $\mathrm{H}_{2} \mathrm{O}$ may be taken up by grain boundary movement, again either at equilibrium or larger concentrations.

from the $\mathrm{Au}$ jacket should only lead to larger $f_{\mathrm{O}_{2}}$ values). We have also considered other chemical variables, including $\mathrm{Na}$ content of the fluid (using $\mathrm{NaOH}$ solutions) and impurities of talc (by sealing talc in the Au capsules as the fluid source). These variables do not appear to have any influence upon the IR spectra of annealed quartz crystals.

Only the deformation experiments repeated in talc assemblies appear to be consistent with the original GriggsBlacic experiments; however, these experiments also reveal a time dependence of strength inconsistent with the solid-state transport of water. Water contents of these samples could not be measured using IR spectroscopy due to scattering losses. In fact, the loss in IR transmittance, combined with the results of optical microscopy, is revealing of the mechanism of water transport. Photomicrographs of these samples (Figure 13), like those of Griggs and Blacic [Blacic, 1975, Figure 7] show, in addition to the development of basal and prismatic deformation lamellae, closely spaced microcracks and fluid inclusions.

Because the principle of effective pressure $P_{e}$ (where $P_{e}=$ $P_{c}-P_{\mathrm{H}_{2} \mathrm{O}}$ ) is rarely applied to flawless single crystals, microcracks in these high-pressure samples have commonly been assumed to be due to unloading stresses at the conclusion of the experiments. Nevertheless, close examination of our single crystals of quartz, as cored, and after annealing (without explicitly applying an end load) in talc assemblies (Figure 13a) reveals the presence of fine, evenly spaced microcracks perpendicular to the axis of the core which are apparently created by the coring process. Given these flaws in unjacketed samples, the effective pressures at elevated water pressures in the vicinity of the cracks must be relatively small. Further observations under crossed nicols (Figure 13b) show the development of basal deformation lamellae, nucleated within this outer rind of fractured sample, in response to nonhydrostatic stresses generated by point contacts and by the relatively strong talc confining medium.

After deformation in talc assemblies (Figure 13c), quartz samples exhibit evidence of ductile deformation, including prismatic as well as basal deformation lamellae, and features suggestive of continued brittle deformation, including microcracks and planar arrays of fluid inclusions. Because precipitation of fluid inclusions from the quartz structure [McLaren et al., 1983] is unlikely in the quench times of these experiments, we believe that these inclusions mark the sites of healed microcracks. The kinetics of crack healing are very rapid [Smith and Evans, 1984], and it is for this reason that we 
believe that brittle processes have previously been dismissed as unimportant under conditions of elevated water pressures. Curiously, Blacic [1975] also reported the presence of fluid inclusions, and Kekulawala et al. [1981], in their IR and transmission electron microscopy study of a quartz crystal annealed in talc by $\mathbf{R}$. Coe and P. Vaughan, were puzzled by its increased water content and abundant fluid inclusions.

If closely spaced microcracks form early in an experiment, water may penetrate samples over much shorter diffusion distances than initially proposed [Blacic, 1981] and resolve the discrepancies between deformation and diffusion studies of quartz. The process of microcracking, though, requires both nonhydrostatic stresses and low effective confining pressures. While these conditions were met in the studies of Griggs and Blacic [1964, 1965], Hobbs and Tullis [1979], Ord and Hobbs [1983], and Mackwell and Paterson [1985] and in the sample annealed in talc by $\mathbf{R}$. Coe and P. Vaughan (reported by Kekulawala et al. [1981]), they were not met in the studies of Kekulawala et al. $[1978,1981]$ and Paterson and Kekulawala [1979] nor in our annealing experiments using $\mathrm{NaCl}$ assemblies. Nonhydrostatic stresses in the experiments of Griggs and Blacic [1964, 1965] and Mackwell and Paterson [1985] were generated, as in our samples annealed in talc, by pressurization of this relatively strong confining medium. Nonhydrostatic stresses were explicitly applied by end-loading samples in the experiments of Hobbs and Tullis [1979] and Ord and Hobbs [1983] and in our deformation tests reported here. Because quartz specimens were deformed in talc assemblies without the use of metal jackets, we suspect that the effective confining pressures in previous studies [e.g., Griggs and Blacic, 1964, 1965] were small. Likewise, we believe that effective pressures were small in experiments where $\mathrm{H}_{2} \mathrm{O}$ was added directly to sample capsules (Hobbs and Tullis [1979], Ord and Hobbs [1983], Mackwell and Paterson [1985], Kekulawala et al. [1981], and annealing experiments of this study).

While we do not argue with the reported effect of water on the ductile strength of quartz [Griggs and Blacic, 1965], we no longer believe that the mechanism of $\mathrm{H}_{2} \mathrm{O}$ uptake was purely diffusional. The extensive undulatory extinction and, in particular, the basal and prismatic deformation lamellae in our samples deformed in talc assemblies (and never observed in dry quartz) support the original findings of Griggs and Blacic [1965]. However, the diffusion rates of molecular water are not rapid and appear to be controlled by oxygen transport. Unfortunately, the competing brittle and ductile deformation mechanisms of the original experiments complicate their interpretation, especially in light of the effects of water, fluid chemistry and $\mathrm{pH}$ upon the rates of microcrack extension [Atkinson, 1984; Dunning et al., 1984] and frictional sliding [Dieterich and Conrad, 1984]. In addition, the low transport rates of water in quartz suggest that determination of its equilibrium solubility will be difficult.

Although more complicated than initially anticipated, the process of water incorporation in the Griggs-Blacic experiments may be very important under natural conditions. If, as we submit, the rates of water uptake into quartz at lower temperatures are controlled by oxygen diffusion, equilibration within the crust may be slow and require long metamorphic events. However, microcracks may assist its uptake by reducing the necessary penetration distances. Investigations of small ductile shear zones in granitic rocks of the Sierra Nevada, California, and near Roses, NE Spain [Segall and Simpson, 1986], suggest that dilatent fracturing and fluid infiltration commonly precede ductile deformation. Examination of one of these shear zones (of the Sierra Nevada) using IR spectroscopy, furthermore, shows a systematic correlation of fluid inclusion water with finite strain [Kronenberg et al., 1984].

A variety of mechanisms may, in fact, be responsible for $\mathrm{H}_{2} \mathrm{O}$ uptake, depending upon the geologic conditions (Figure 14). In addition to volume diffusion and crack-assisted diffusion, molecular water may be incorporated by diffusion along dislocation cores [Tullis and Yund, 1985] or under conditions of rapid crystal growth and grain boundary movement. Studies of quartz synthesis [Barnes et al., 1976] have shown that molecular water can be incorporated as a nonequilibrium defect at rapid growth rates. Water contents of rapidly grown quartz crystals would therefore not be limited to equilibrium solubilities. Water may also be taken up from grain boundary films by grain boundary movement. In this case, water would be swept up at equilibrium concentrations [Kirby and Kronenberg, 1984b] or at nonequilibrium concentrations by a similar process as that in rapid crystal growth.

Interpretations of the ductile deformation of quartz under geologic conditions will ultimately depend upon our understanding of water weakening. Because of the slow diffusion rates of water and the competing deformation mechanisms in experiments performed on hydrothermally annealed natural crystals, however, we are left with the results for dry natural crystals and for wet synthetic crystals as the basis of hydrolytic weakening. Because few large natural crystals (with exceptions such as amethysts and citrines) contain large concentrations of finely dispersed molecular water, Paterson and Kekulawala [1979] have questioned the relevance of synthetic quartz rheologies to naturally occurring quartz. Whether or not the results of wet synthetic quartz apply to fine-grained quartz tectonites must therefore await the direct measurement of their intracrystalline water contents.

\section{Conclusions}

The results of IR spectroscopy and deformation experiments on single crystals of natural quartz annealed hydrothermally at elevated pressures and temperatures lead to the following conclusions:

1. The diffusive uptake of interstitial hydrogen $\mathbf{H}_{i}$ into quartz is the same at high pressures $\left(P_{\mathrm{H}_{2} \mathrm{O}}=400-1550 \mathrm{MPa}\right)$ as at near-ambient pressures.

2. The equilibrium solubility of $\mathbf{H}_{i}$ in quartz is independent of $T, P_{\mathrm{H}_{2} \mathrm{O}}$, and fluid chemistry over the experimental conditions tested; instead, it is a function of the $\mathrm{Al}$ content by the local charge neutrality condition $\left[\mathrm{H}_{i}\right]=\left[\mathrm{Al}_{\mathrm{Si}}{ }^{\prime}\right]$.

3. Significant concentrations of molecular water $\left(\mathrm{H}_{2} \mathrm{O}\right)_{i}{ }^{x}$ are not taken up by quartz single crystals in experimental times, even at elevated $\boldsymbol{P}_{\mathrm{H}_{2} \mathrm{O}}$.

4. Interstitial $\mathbf{H}$ defects have no measurable influence on the yield strength of quartz.

5. It appears that microcracking and crack-assisted diffusion of water were important processes in the original hydrolytic weakening experiments of Griggs and Blacic [1964, 1965], as well as in several later studies in which weakening of natural single crystals was reported. This may be the primary source of discrepancies, both within the mechanics literature and with the diffusion data for quartz.

Acknowledgments. This study benefited from helpful discussions with many of our colleagues, and we can only be incomplete when we include those with J. Blacic, J. Christie, P. Dennis, B. Giletti, H. Green, B. Hobbs, M. Linker, S. Mackwell, A. Ord, M. Paterson, M. Rovetta, P. Segall, J. Tullis, T. Tullis, and R. Yund. We thank J. Christie, who generously provided samples of the Brazilian quartz crystal used in this study. We thank B. Monroe whose efficiency and flawless preparation of manuscripts and tables we so depend on. 


\section{REFERENCES}

Aines, R. D., and G. R. Rossman, Water in minerals? A peak in the infrared, J. Geophys. Res., 89, 4059-4071, 1984.

Aines, R. D., S. H. Kirby, and G. R. Rossman, Hydrogen speciation in synthetic quartz, Phys. Chem. Miner., 11, 204-212, 1984.

Alpert, N. L., W. E. Keiser, and H. A. Szymanski, IR Theory and Practice of Infrared Spectroscopy, 380 pp., Plenum, New York, 1970.

Anderson, G. M., and C. W. Burnham, The solubility of quartz in supercritical water, Am. J. Sci., 263, 494-511, 1965.

Atkinson, B. K., Subcritical crack growth in geological materials, $J$. Geophys. Res., 89, 4077-4114, 1984.

Baëta, R. D., and K. H. G. Ashbee, Plastic deformation and fracture of quartz at atmospheric pressure, Philos. Mag., 15, 931-938, 1967.

Baëta, R. D., and K. H. G. Ashbee, Slip systems in quartz, I, Experiments, Am. Mineral., 54, 1551-1573, 1969a.

Baëta, R. D., and K. H. G. Ashbee, Slip systems in quartz, II, Interpretation, Am. Mineral., 54, 1574-1582, 1969 b.

Balderman, M. A., The effect of strain rate and temperature on the yield point of hydrolytically weakened synthetic quartz, $J$. Geophys. Res., 79, 1647-1652, 1974.

Ball, A., and G. Glover, Dislocation climb deformation in quartz, Bull. Mineral., 102, 188-194, 1979.

Bambauer, H. U., Spurenelement gehalte und $\gamma$-farbzentren in quarzen aus zerrklüften der Schweizer Alpen, Schweiz. Mineral. Petrogr. Mitt., 41, 335-369, 1961.

Bambauer, H. U., G. O. Brunner, and F. Laves, Light scattering of heat-treated quartz in relation to hydrogen containing defects, $\mathrm{Am}$. Mineral., 54, 718-724, 1969.

Barnes, H. L., and W. G. Ernst, Ideality and ionization in hydrothermal fluids: The system $\mathrm{MgO}-\mathrm{H}_{2} \mathrm{O}-\mathrm{NaOH}, A m$. J. Sci., 261, 129-150, 1963.

Barnes, R. L., E. D. Kolb, R. A. Landise, E. E. Simpson, and K. M. Kroupa, Production and perfection of $z$-face quartz, J. Cryst. Growth, 34, 189-197, 1976.

Bastin, J. A., and E. W. J. Mitchell, Light scattering from heat treated synthetic quartz, Am. Mineral., 46, 1227-1244, 1961.

Blacic, J. D., Hydrolytic weakening of quartz and olivine, Ph.D. thesis, 205 pp., Univ. of Calif., Los Angeles, 1971.

Blacic, J. D., Plastıc deformation mechanisms in quartz: The effect of water, Tectonophysics, 27, 271-294, 1975.

Blacic, J. D., Water diffusion in quartz at high pressure: Tectonic implications, Geophys. Res. Lett., 8, 721-723, 1981.

Brace, W. F., and R. J. Martin, A test of the law of effective stress for crystalline rocks of low porosity, Int. J. Rock Mech, Min. Sci., 5, 415-426, 1968.

Choudhury, A., D. W. Palmer, G. Amsel, H. Curieu, and P. Baruch, Study of oxygen diffusion in quartz using the nuclear reaction ${ }^{18} \mathrm{O}(\rho, \alpha)^{15} \mathrm{~N}$, Solid State Commun., 3, 119-122, 1965.

Colthup, N. B., L. H. Daly, and S. E. Wiberley, Introduction to Infrared and Raman Spectroscopy, 511 pp., Academic, Orlando, Fla., 1964.

Crank, J., The Mathematics of Diffusion, 414 pp., Oxford University Press, London, 1975.

Dennis, P. F., Oxygen self-diffusion in quartz under hydrothermal conditions, J. Geophys. Res., 89, 4047-4057, 1984.

Dieterich, J. H., and G. Conrad, Effect of humidity on time- and velocity-dependent friction in rocks, J. Geophys. Res., 89, 4196$4202,1984$.

Dodd, D. M., and D. B. Fraser, The $3000-3900 / \mathrm{cm}$ absorption bands and anelasticity in crystalline quartz, J. Phys. Chem. Solids, 26, 673-686, 1965.

Dodd, D. M., and D. B. Fraser, Infrared studies of the variation of $\mathrm{H}$-bonded $\mathrm{OH}$ in synthetic alpha-quartz, Am. Mineral., 52, 149$160,1967$.

Dunning, J. D., D. Petrovski, J. Schuyler, and A. Owens, The effects of aqueous chemical environments on crack propagation in quartz, J. Geophys. Res., 89, 4115-4123, 1984.

Freer, R., Diffusion in silicate minerals and glasses: A data digest and guide to the literature, Contrib. Mineral. Petrol., 76, 440-454, 1981.

Freer, R., and P. F. Dennis, Oxygen diffusion studies, I, A preliminary ion microprobe investigation of oxygen diffusion in some rock forming minerals, Mineral. Mag., 45, 179-192, 1982.

French, B. M., Some geological implications of equilibrium between graphite and a C-H-O gas at high temperatures and pressures, Rev. Geophys., 4, 223-253, 1966.

Fyfe, W. S., N. J. Price, and A. B. Thompson, Fluids in the Earth's Crust, Developments in Geochemistry 1, 383 pp., Elsvier Scientific, New York, 1978.
Giletti, B. J., and R. A. Yund, Oxygen diffusion in quartz, J. Geophys. Res., 89, 4039-4046, 1984.

Gilettí, B. J., M. P. Semet, and R. A. Yund, Oxygen self-diffusion measured in silicates using an ion microprobe, Eos. Trans. AGU, $57,350,1976$.

Greenwood, H. J., The synthesis and stability of anthophyllite, $J$. Petrol., 4, 317-351, 1963.

Griggs, D. T., Hydrolytic weakening of quartz and other silicates, Geophys. J. R. Astron. Soc., 14, 19-32, 1967.

Griggs, D. T., A model of hydrolytic weakening in quartz, J. Geophys. Res., 79, 1655-1661, 1974.

Griggs, D. T., and J. D. Blacic, The strength of quartz in the ductile regime, Eos Trans. $A G U, 45,102-103,1964$.

Griggs, D. T., and J. D. Blacic, Quartz: Anomalous weakness of synthetic crystals, Science, 147, 292-295, 1965.

Handin, J., R. V. Hager, Jr., M. Friedman, and J. N. Feather, Experimental deformation of sedimentary rocks under confining pressure: pore-pressure tests, Am. Assoc. Pet. Geol. Bull., 47, 717-755, 1963.

Haul, R., and G. Dümbgen, Untersuchung der sauerstoffbeweglichkeit in titandioxid, quarz und quarzglas mit hilte des heterogenen isotopenaustauches, $Z$. Elektrochem., 66, 636-641, 1962.

Hirsch, P. B., Plastic deformation and electronic mechanisms in semiconductors and insulators, J. Phys. C, 42, 149-160, 1981.

Hobbs, B. E., The influence of metamorphic environment upon the deformation of minerals, Tectonophysics, 78, 335-383, 1981.

Hobbs, B. E., and T. E. Tullis, The influence of pressure on hydrolytic weakening in quartz, Eos Trans. AGU, 60,370, 1979.

Hobbs, B. E., A. C. McLaren, and M. S. Paterson, Plasticity of single crystals of synthetic quartz, in Flow and Fracture of Rocks, Geophys. Monograph Ser., vol. 16, edited by H. C. Heard et al., pp. 29-35, AGU, Washington, D. C., 1972.

Hubbert, M. K., and W. W. Rubey, Role of fluid pressure in mechanics of overthrust faulting, 1, Mechanics of fluid-filled porous solids and its application to overthrust faulting, Geol. Soc. Am. Bull., 70, 115-166, 1959.

Hubbert, M. K., and D. G. Willis, Mechanics of hydraulic fracturing, Trans. Am. Inst. Min. Metall. Pet. Eng., 210, 153-168, 1957.

Huebner, J. S., Buffering techniques for hydrostatic systems at elevated pressures, in Research Techniques for High Pressure and High Temperature, edited by G. C. Ulmer, pp. 123-177, Springer-Verlag, New York, 1971

Irving, A. J., W. L. Huang, and P. J. Wyllie, Phase relations of portlandite $\mathrm{Ca}(\mathrm{OH})_{2}$ and brucite $\mathrm{Mg}(\mathrm{OH})_{2}$ to 33 kilobars, $A m$. J. Sci., 277, 313-321, 1977.

Jaoul, O., Sodium weakening of Heavitree quartzite: Preliminary results, J. Geophys. Res., 89, 4271-4280, 1984.

Kats, A., Hydrogen in alpha-quartz, Philips Res. Rep., 17, 1-31, 133$279,1962$.

Kats, A., Y. Haren, and J. M. Stevels, Hydroxyl groups in $\beta$-quartz, Phys. Chem. Glasses, 3, 69-75, 1962.

Kekulawala, K. R. S. S., M. S. Paterson, and J. N. Boland, Hydrolytic weakening in quartz, Tectonophysics, 46, T1-T6, 1978.

Kekulawala, K. R. S. S., M. S. Paterson, and J. N. Boland, An experimental study of the role of water in quartz deformation, in Mechanical Behavior of Crustal Rocks, Geophys. Monogr. Ser., vol. 24, edited by N. L. Carter et al., pp. 49-59, AGU, Washington, D. C., 1981.

Kirby, S. H., Creep of synthetic alpha quartz, Ph.D. thesis, Univ. of Calif., Los Angeles, 1975.

Kirby, S. H., and A. K. Kronenberg, Deformation of clinopyroxenite: Evidence for a transition in flow mechanisms and semibrittle behavior, J. Geophys. Res., 89, 3177-3192, 1984a.

Kirby, S. H., and A. K. Kronenberg, Diffusion-induced grainboundary motion (DIGM) and diffusion-induced recrystallization (DIR): Applications to the rheology of rocks, Eos Trans. AGU, 65, 1098, 1984b.

Kirby, S. H., and J. W. McCormick, Creep of hydrolytically weakened synthetic quartz crystals oriented to promote (2110)[0001] slip: A brief summary of work to date, Bull. Mineral., 102, 124-137, 1979.

Kronenberg, A. K., and J. Tullis, Flow strengths of quartz aggregates: Grain size and pressure effects due to hydrolytic weakening, $J$. Geophys. Res., 89, 4281-4297, 1984.

Kronenberg, A. K., G. H. Wolf, and P. Segall, Variations in intragranular water within a strain gradient: FTIR traverse across a ductile shear zone, Eos Trans. $A G U, 65,1098,1984$.

Linker, M. F., and S. H. Kirby, Anisotropy in the rheology of hydrolytically weakened synthetic quartz crystals, in Mechanical Behavior of Crustal Rocks, Geophys., Monogr. Ser., vol. 24, edited by N. L. Carter et al., pp. 29-48, AGU, Washington, D. C., 1981.

Linker, M. F., S. H. Kirby, A. Ord, and J. M. Christie, Effects of 
compression direction on the plasticity and rheology of hydrolytically weakened synthetic quartz crystals at atmospheric pressure, J. Geophys. Res., 89, 4241-4256, 1984.

Mackwell, S. J., and M. S. Paterson, Water-related diffusion and deformation effects in quartz at pressures of 1500 and $300 \mathrm{MPa}$, in Point Defects in Minerals, Geophys. Monogr. Ser., vol. 31, edited by R. N. Schock, pp. 141-150, AGU, Washington, D. C., 1985.

McLaren, A. C., R. F. Cook, S. T. Hyde, and R. C. Tobin, The mechanisms of the formation and growth of water bubbles and associated dislocation loops in synthetic quartz, Phys. Chem. Miner., 9, 79-94, 1983.

Morrison-Smith, D. J., M. S. Paterson, and B. E. Hobbs, An electron microscope study of plastic deformation in single crystals of synthetic quartz, Tectonophysics, 33, 43-79, 1976.

Ord, A., and B. E. Hobbs, Oxygen dependence of the hydrolytic weakening effect in quartz, Eos Trans. AGU, 64, 839, 1983.

Ord, A., and B. E. Hobbs, Experimental control of the waterweakening effect in quartz, in Mineral and Rock Deformation: Lab oratory Studies - The Paterson Volume, Geophys. Monogr. Ser., vol. 36, edited by B. E. Hobbs and H. C. Heard, pp. 51-72, AGU Washington, D. C., 1986.

Paterson, M. S., The determination of hydroxyl by infrared absorption in quartz, silicate glasses and similar materials, Bull. Mineral., 105, 20-29, 1982.

Paterson, M. S., and K. R. S. S. Kekulawala, The role of water in quartz deformation, Bull. Mineral., 102, 92-98, 1979.

Schachtner, R., and H. G. Sockel, Study of oxygen diffusion in quartz by activation analysis, in Reactivity of Solids, Proceedings International Symposium (8th), edited by J. Wood et al., pp. 605-609, Plenum, New York, 1977.

Schramke, J. A., D. M. Kerrick, and J. G. Blencoe, Experimental determination of the brucite $=$ periclase + water equilibrium with a new volumetric technique, Am. Mineral., 67, 269-276, 1982.

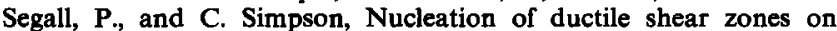
dilatant fractures, Geology, 14, 56-59, 1986.

Shaffer, E. W., J. Shi-Lan Sang, A. R. Cooper, and A. H. Heuer,
Diffusion of tritiated water in $\beta$-quartz, Geochemical Transport and Kinetics, edited by A. W. Hofmann et al., Carnegie Inst. Washington Publ., 634, 131-138, 1974.

Smith, D. L., and B. Evans, Diffusional crack healing in quartz, $J$. Geophys. Res., 89, 4125-4136, 1984.

Swalin, R. A., Thermodynamics of Solids, 387 pp., John Wiley, New York, 1972.

Trepied, L., and J. C. Doukhan, Evidence of $\langle c+a\rangle$ dislocations in synthetic quartz single crystals compressed along the $c$ axis, Bull. Mineral., 105, 176-180, 1982.

Tullis, J., and R. A. Yund, Hydrolytic weakening of quartz aggregates: Requirement for rapid water penetration, Eos Trans. $A G U$, $66,1084,1985$

Tullis, J. A., G. L. Shelton, and R. A. Yund, Pressure dependences of rock strength: Implications for hydrolytic weakening, Bull. Mineral., 102, 110-114, 1979.

Weber, J. N., and R. Roy, Complex stable $\rightleftharpoons$ metastable solid reactions illustrated with the $\mathrm{Mg}(\mathrm{OH})_{2} \rightleftharpoons \mathrm{MgO}$ reaction, $A m$. J. Sci., 263 , 668-677, 1965.

Yamaoka, S., O. Fukanaga, and S. Saito, Phase equilibrium in the system $\mathrm{MgO}-\mathrm{H}_{2} \mathrm{O}$ at high temperatures and very high pressures, $J$. Am. Ceram. Soc., 53, 179-181, 1970.

R. D. Aines, Lawrence Livermore National Laboratory, Earth Sciences Department, Livermore, CA 94550.

S. H. Kirby, U.S. Geological Survey, 345 Middlefield Road, MS/977, Menlo Park, CA 94025.

A. K. Kronenberg, Center for Tectonophysics, College of Geosciences, Texas A\&M University, College Station, TX 77843.

G. R. Rossman, Division of Geological and Planetary Sciences, California Institute of Technology, Pasadena, CA 91125.

(Received October 3, 1985;

revised June 20, 1986;

accepted June 24, 1986.) 